\title{
Modelling the degradation of vibration characteristics of reinforced concrete beams due to flexural damage
}

\author{
W. I. Hamad* J. S. Owen and M. F. M. Hussein ${ }^{\dagger}$ \\ Centre for Structural Engineering and Construction (CSEC), \\ Faculty of Engineering, University of Nottingham, University Park, Nottingham, NG7 2RD, UK
}

\begin{abstract}
This paper presents an improved crack model incorporating non-linearity of flexural damage in concrete to reproduce changes in vibration properties of cracked reinforced concrete beams. A reinforced concrete beam model with multiple-distributed flexural cracks is developed, in which the cracked regions are modelled using the fictitious crack approach and the undamaged parts are treated in a linear-elastic manner. The model is subject to incremental static four-point bending and its dynamic behaviour is examined using different sinusoidal excitations including swept sine and harmonic signals. From the swept sine excitations, the model simulates changes in resonant frequency with increasing damage. The harmonic excitations are utilised to investigate changes in modal stiffness extracted from the restoring force surfaces, and changes in the level of non-linearity deduced from the appearance of super-harmonics in the frequency domain. The simulation results are compared with experimental data of reinforced concrete beams subject to incremental static four-point bending. The comparisons revealed that the proposed crack model is able to quantitatively predict changes in vibration characteristics of cracked reinforced concrete beams. Changes are sensitive to support stiffness, where the sensitivity increases with stiffer support conditions. Changes in the level of non-linearity with damage are not suitable for damage detection in reinforced concrete structures because they do not follow a monotonic trend.
\end{abstract}

Keywords: reinforced concrete beams; vibration-based damage detection; non-linear vibration; flexural crack modelling; vibration measurements

${ }^{*}$ Corresponding author, presently at the Department of Engineering, University of Cambridge. E-mail: wih22@cam.ac.uk. Tel: +44 (0)1223 748535

${ }^{\dagger}$ Presently at the College of Engineering, University of Qatar. 


\begin{tabular}{|c|c|}
\hline \multicolumn{2}{|c|}{ Nomenclature } \\
\hline$a_{0}, a_{1}$ & proportionality factors defined by Eq. 6 \\
\hline $\mathbf{C}_{G}$ & global damping matrix \\
\hline$E_{c}$ & concrete Young's modulus \\
\hline$E_{c}^{\prime}$ & gradient of the unloading and reloading paths \\
\hline$E_{s}$ & steel Young's modulus \\
\hline$f_{c}$ & concrete stress \\
\hline$f_{c u}$ & ultimate compressive strength \\
\hline$f_{c t}$ & concrete tensile strength \\
\hline$f_{\text {eu }}$ & envelope unloading concrete stress \\
\hline$f_{e r}$ & envelope reloading concrete stress \\
\hline$f_{L}$ & lower level stress \\
\hline$f_{o}$ & concrete stress at linear-elastic state \\
\hline$f_{s}$ & steel stress \\
\hline$f_{S}$ & sampling frequency \\
\hline$f(u, \dot{u})$ & internal restoring force of the system \\
\hline$f_{y}$ & yield strength of steel \\
\hline$F_{c}$ & total force on the section \\
\hline$F(t)$ & excitation force \\
\hline G & function defines undamaged parts and cracked regions \\
\hline$h_{c}$ & width of cracked zone \\
\hline$I_{c}$ & second moment of area \\
\hline $\mathbf{J}$ & Jacobian matrix \\
\hline$k_{s}$ & stiffness of vertical springs \\
\hline $\mathbf{K}$ & element stiffness matrix \\
\hline $\mathbf{K}_{G}$ & global stiffness matrix \\
\hline $\mathbf{K}_{\text {mod }}$ & modified stiffness matrix \\
\hline$l$ & element length \\
\hline $\bar{m}$ & uniform mass per unit length \\
\hline M & consistent-mass matrix \\
\hline $\mathbf{M}_{G}$ & global mass matrix \\
\hline $\mathbf{P}_{e x t}$ & external forces \\
\hline $\mathbf{U}_{a p p}$ & applied displacements \\
\hline $\mathbf{U}_{\text {corr }}$ & corresponding nodal displacements and rotations \\
\hline $\mathbf{U}_{u n}$ & unknown nodal displacements and rotations \\
\hline
\end{tabular}




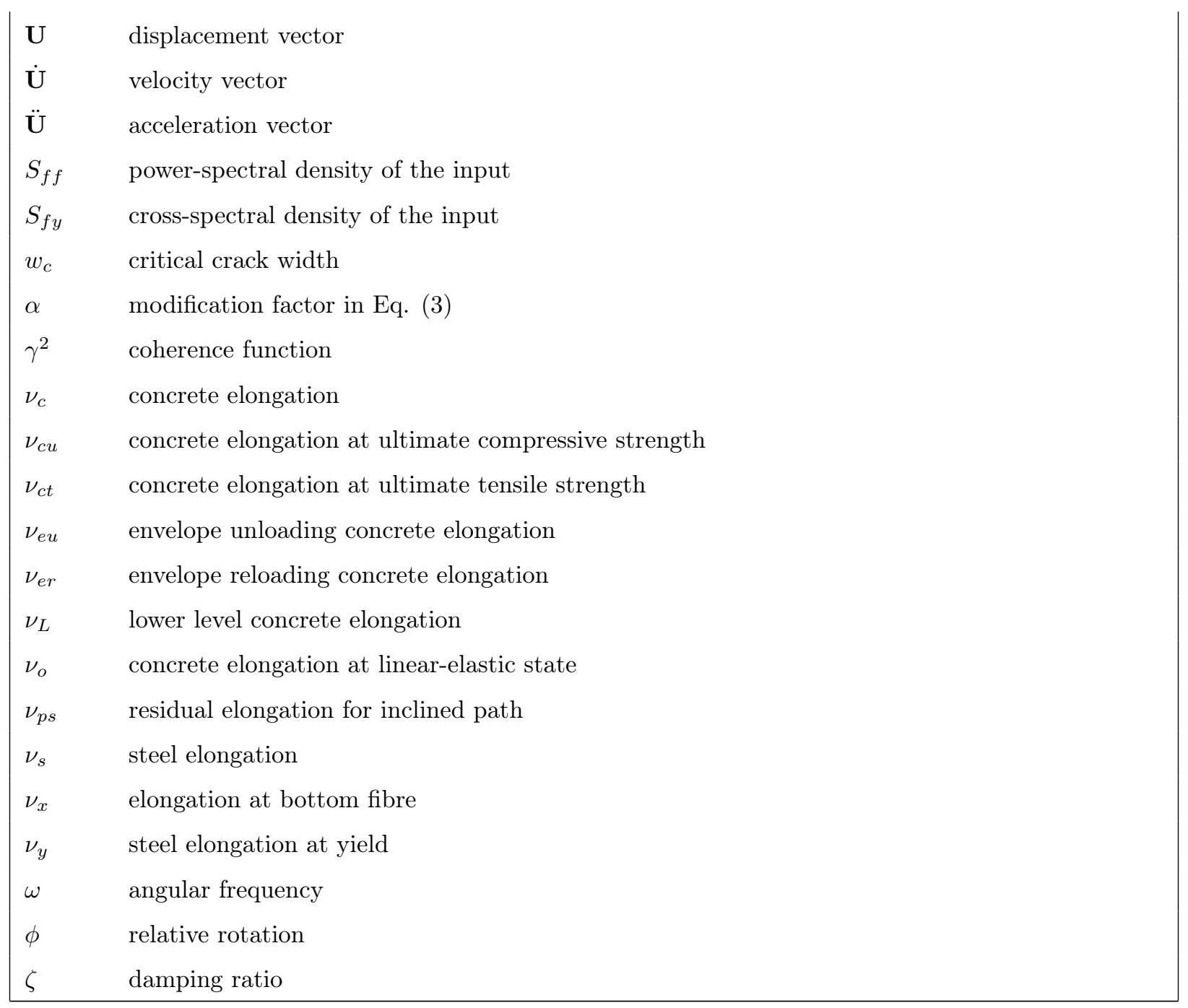

\section{Introduction}

The importance of using global and automated damage detection and monitoring techniques for existing structures has been widely recognised in developed countries. One of these global damage detection methods is based on changes in vibration characteristics and has been a subject of investigation for the last three decades [1 4]. The method is primarily driven by the fact that the presence of damage or deterioration in a structure induces changes in its local stiffness which in turn influence the global dynamic behaviour of the structure [5]. Furthermore, vibration data can easily be collected by positioning just a few sensors on the structure.

The effects of damage in structures can be classified as linear or non-linear. When an initially linear-elastic structure remains linear-elastic after damage, this is defined as linear damage. The majority of literature on damage detection presumes that the vibration properties are not related to the amplitude of oscillation and hence consider linear damage. However, damage often causes a structure that initially behaved in a 
linear manner to exhibit a non-linear response. A fatigue crack that consequently opens and closes under the ambient vibration is considered as an example of non-linear damage. Damaged reinforced concrete (RC) structures are also found to exhibit non-linear manner across vibration cycles [6] 6 ].

Previous models of vibrating cracked beams used either open crack models, i.e. crack is predominantly open or breathing crack models, i.e. crack opens and closes during the oscillation. The idea of the open crack model is that the reduced stiffness, at the crack location, remains constant irrespective of the magnitude of the applied load whilst the structure is oscillating. However, this model has been found to be unreliable as most cracks open and close across the vibration cycle. This change between opening and closure in turn causes the stress around the crack zone to alternate between tension at the opening state and compression at the closure state. Thus, researchers have suggested breathing crack models which include the compressive action when the crack closes to model the vibration of cracked structures [9 11].

The adoption of breathing crack models was found to be inappropriate for damaged structures that exhibit non-linear vibration response [12. This is because breathing crack models neglect the inherent transition process from crack open to crack closed. It has therefore been suggested to model the response of cracked beams using non-linear crack models that take into account this transition [13 15]. In these models, the damaged stiffness was generally represented as a function of the undamaged stiffness to ensure alteration at any time during the oscillation.

For example, Cheng et al. [16] expressed the stiffness as a function of the undamaged stiffness, the difference between the undamaged and damaged stiffness and the excitation frequency. The stiffness model was then incorporated into the equation of motion of a damped single-degree-of-freedom (SDOF) system. Neild et al. [14 developed a time-stepping model of a vibrating cracked beam divided into short blocks joined with rotational and transverse springs representing bending and shear deformation respectively. The cracks were described by adjusting the stiffness of the rotational springs, where the flexibility of the springs at the positions of the cracks was continuously changing across the vibration cycles. This procedure enabled the modelling of a breathing crack or a more complex fatigue crack.

Although some of these models have replicated the non-linear phenomenon, they have not reproduced the experimental behaviour quantitatively. This is particularly true for cracked RC beams whose vibration behaviour is reported to be non-linear. The problem is believed to be due to the lack of clear understanding of both the crack formation process and the vibration behaviour about the residual deformation. An improved model of fracture in concrete is thus required in order to better simulate degradation in vibration characteristics of cracked RC beams.

The aim of this paper is hence to determine whether a flexural crack model incorporating non-linearity is able to quantitatively reproduce changes in vibration characteristics of cracked $\mathrm{RC}$ beams. A model of RC beam with multiple-distributed cracks subject to four-point bending under displacement control is developed. The model consists of a number of beam elements, some of which describe the undamaged parts and others represent the cracked regions. The undamaged parts are modelled in a linear-elastic manner whereas the 
cracked regions are simulated using the so-called fictitious crack model (FCM). The dynamic behaviour of the model is examined at a number of damage levels using different sinusoidal excitations including swept sine and harmonic signals. The efficacy of the model is assessed against experimental results of RC beams subject to incremental static four-point bending. The comparisons include both the cracking behaviour and the degradation of linear and non-linear vibration characteristics, such as restoring force surface and appearance of super-harmonics, with increasing damage.

The layout of the paper is as follows. Section 2 presents a brief background about the existing modelling techniques of cracking in concrete. The formulation of the model, the adopted constitutive relationships and the solution algorithm are given in section 3 The experimental work on the $\mathrm{RC}$ beams is presented in section 4 while section 5 compares between the model's simulation and the experimental results. Finally, the findings of the work and concluding remarks are given in section 6

\section{Modelling of cracking in concrete}

The mechanism of crack formation and propagation in concrete has received significant research effort over the last three decades. Many numerical models of fracture in concrete have been developed based on a number of modelling approaches such as plasticity models, microplane models and fracture mechanics models. Each of these approaches has used different formulations of the constitutive relationships which describe the material behaviour under loading.

Models based on the fracture mechanics approach are found to be suitable to describe the fracture process of quasi-brittle materials due to damage and micro-cracking while maintaining simple calculations. One of the fracture mechanics models that is suitable for describing cracking in concrete is the FCM. It describes cracks using stress against crack opening relationship where cohesive stress at the crack surface varies between the tensile strength of material at the crack tip and zero at a characteristic crack opening (Fig. 1). These cohesive stresses, present in the fracture process zone (FPZ), are due to stress transfer in micro-ligaments between micro-cracks plus some frictional stresses due to aggregates and material inhomogeneities in the crack faces [17].

[Figure 1 about here.]

The authors [18] have utilised the FCM in developing an efficient model of the monotonic and cyclic flexural cracking behaviour of a plain concrete (PC) prism with a single crack in the midspan. In their model, the constitutive laws of [19, 20] were adopted to scrutinise the cyclic flexural behaviour, and the crack was assumed to form when the tensile strength of concrete $\left(f_{c t}\right)$ is reached. In addition, the effect of the crack was assumed to spread over a zone of width $\left(h_{c}\right)$, known as the equivalent elastic zone. The width of this zone is a vital parameter in the model as it defines the stiffness of the cracked zone. According to [21, 22], the width of the elastic zone was taken as half the overall height of the cross-section, and it 
was also confirmed by the authors [18] that when $h_{c}$ is set to half the height of the cross-section a good agreement with the experimental measurements is achieved. The equivalent elastic zone was discretised into a number of longitudinal layers in the same way as the fibre element modelling approach. The material on the crack formation path was assumed to be in one of three possible states: (a) linear-elastic state before crack formation, (b) a fracture state where material is softening due to the cohesive forces in the FPZ, and (c) a state of zero stress when the crack width is beyond the critical crack width $\left(w_{c}\right)$.

Having modelled the monotonic and cyclic flexural behaviour of the PC prism model in [18, the bending behaviour of RC beams under four-point bending could be modelled adopting the same concept. However, unlike PC prisms, multiple-distributed cracks do form in RC beams with increasing load. Usually, tension cracks occur when the bending stresses reach the tensile strength of concrete at certain sections of the beam. At the crack location, the contribution of concrete in transmitting the tensile force becomes negligible and a discontinuity region, i.e. discontinuity in stress transfer, develops on both sides of the crack. In this region, concrete is reactivated to carry part of the tensile force by virtue of the bond between concrete and steel, and with increasing load, another crack forms just outside the discontinuity region of the adjacent crack. This process continues until multiple cracks form at almost regular spacing along the beam depending on the length of the discontinuity region which depends on concrete bond and tensile stress [23].

With this understanding, a cracked RC beam model can be divided into a number of blocks, where cracked positions are represented by a crack model and undamaged sections are described by a beam model. However, this requires a-priori knowledge of the positions at which cracks form when the tensile strength of concrete is reached. Previous experiments on RC beams have indicated that cracks form at spacings approximately equal to the spacing of shear links [24, 25]. Therefore, cracked regions can be distributed at spacings governed by the locations of the shear links while elements in between cracked regions can be treated in a linear-elastic manner. A detailed description of the formulation of the model follows in the following sections.

\section{Modelling strategy}

A RC beam model with distributed cracks and supported on vertical springs with stiffness $\left(k_{s}\right)$ is developed. The model consists of a number of beam elements; some of which describe the cracked regions and others represent the undamaged parts. The model is subject to four-point bending under displacement-control as shown in Fig. 2 .

[Figure 2 about here.]

The cracked regions are modelled using the FCM in the same manner of the PC prism model in [18], whereas a linear-elastic approach is adopted for the undamaged parts. The length of the undamaged parts $\left(l_{2}\right)$ is considered as the clear spacing between the cracked regions, except for the outer undamaged parts where the length is $l_{1}$. The assumptions followed in developing the model are: 
- A flexural crack is assumed to develop in the tension zone.

- The strain softening behaviour of concrete in tension is assumed to play the dominant role in causing the non-linear behaviour. Other factors such as steel-concrete bond and interface behaviour are neglected as they have little effect on the non-linearity [26].

- Only the uniaxial behaviour of concrete is considered and the effect of confinement is neglected.

- Only tensile and compressive reinforcement is considered and the effect of shear links is neglected.

- Plane sections remain plane at the interface with the cracked regions.

\subsection{Model formulation}

The approach adopted to formulate the PC prism model in [18 cannot be used in the present RC beam model. The approach requires that the displacements and rotations at the ends of the cracked region are equal with the rotations being in opposite direction. This was the case for the PC prism model where there is only one cracked region at the section of symmetry. However, in the RC beam model there are multiple distributed cracked regions that are located where the rotations and displacements at the two ends of any cracked region are not equal. Therefore, the RC beam model is formulated using the direct stiffness method. Each element is described by a matrix relating the end displacements and rotations to the end forces and moments (Fig. 33).

[Figure 3 about here.]

In the following sections, stiffness, mass and damping matrices that are used to describe the undamaged parts and the cracked regions of the RC beam model (Fig. 2) are presented.

\subsubsection{Stiffness matrix}

The end forces and moments in Fig. 3 are related to end displacements and rotations as,

$$
\left[\begin{array}{c}
F_{1} \\
M_{1} \\
F_{2} \\
M_{2}
\end{array}\right]=\mathbf{K}\left[\begin{array}{c}
\Delta_{1} \\
\phi_{1} \\
\Delta_{2} \\
\phi_{2}
\end{array}\right]
$$

where $\mathbf{K}$ is the beam element stiffness matrix described by

$$
\mathbf{K}=\left[\begin{array}{cccc}
\frac{12 E_{c} I_{c}}{l^{3}} & \frac{6 E_{c} I_{c}}{l^{2}} & -\frac{12 E_{c} I_{c}}{l^{3}} & \frac{6 E_{c} I_{c}}{l^{2}} \\
\frac{6 E_{c} I_{c}}{l^{2}} & \frac{4 E_{c} I_{c}}{l} & -\frac{6 E_{c} I_{c}}{l^{2}} & \frac{2 E_{c} I_{c}}{l} \\
-\frac{12 E_{c} I_{c}}{l^{3}} & -\frac{6 E_{c} I_{c}}{l^{2}} & \frac{12 E_{c} I_{c}}{l^{3}} & -\frac{6 E_{c} I_{c}}{l^{2}} \\
\frac{6 E_{c} I_{c}}{l^{2}} & \frac{2 E_{c} I_{c}}{l} & -\frac{6 E_{c} I_{c}}{l^{2}} & \frac{4 E_{c} I_{c}}{l}
\end{array}\right]
$$


The stiffness matrix $(\mathbf{K})$ is used for the undamaged parts, where the element length $(l)$ is taken as either $l_{1}$ or $l_{2}$ depending on the undamaged part location (Fig. 2), $E_{c}$ is the concrete Young's modulus, and $I_{c}$ is the second moment of area for the equivalent RC section. However, the cracked regions are represented by a modified version of the beam element stiffness matrix $\left(\mathbf{K}_{\text {mod }}\right)$,

$$
\mathbf{K}_{\text {mod }}=\left[\begin{array}{cccc}
\frac{12 E_{c} I_{c}}{h_{c}^{3}} & \frac{6 E_{c} I_{c}}{h_{c}^{2}} & -\frac{12 E_{c} I_{c}}{h_{c}^{3}} & \frac{6 E_{c} I_{c}}{h_{c}^{2}} \\
\frac{6 E_{c} I_{c}}{h_{c}} & \frac{3 E_{c} I_{c}}{h_{c}}+\frac{\alpha}{2} & -\frac{6 E_{c} I_{c}}{h_{c}^{2}} & \frac{3 E_{c} I_{c}}{h_{c}}-\frac{\alpha}{2} \\
-\frac{12 E_{c} I_{c}}{h_{c}^{3}} & -\frac{6 E_{c} I_{c}}{h_{c}^{2}} & \frac{12 E_{c} I_{c}}{h_{c}^{3}} & -\frac{6 E_{c} I_{c}}{h_{c}^{2}} \\
\frac{6 E_{c} I_{c}}{h_{c}^{2}} & \frac{3 E_{c} I_{c}}{h_{c}}-\frac{\alpha}{2} & -\frac{6 E_{c} I_{c}}{h_{c}^{2}} & \frac{3 E_{c} I_{c}}{h_{c}}+\frac{\alpha}{2}
\end{array}\right]
$$

where $\alpha$ is the modification factor of the elements corresponding to end moments and rotations calculated from the rotational stiffness of the FCM. The derivation of the modified stiffness matrix is given in Appendix A. The global stiffness matrix $\left(\mathbf{K}_{G}\right)$ is constructed by assembling the matrices of the undamaged parts with those of the cracked regions.

\subsubsection{Mass matrix}

The consistent-mass matrix $(\mathbf{M})$ is adopted to describe both undamaged parts and cracked regions,

$$
\mathbf{M}=\frac{\bar{m} l}{420}\left[\begin{array}{cccc}
156 & 22 l & 54 & -13 l \\
22 l & 4 l^{2} & 13 l & -3 l^{2} \\
54 & 13 l & 156 & -22 l \\
-13 l & -3 l^{2} & -22 l & 4 l^{2}
\end{array}\right]
$$

in which $\bar{m}$ is the uniform mass per unit length. The consistent-mass matrix is chosen as it gives more accurate results than the lumped-mass matrix, although it requires more computational cost [27, Chapter 10]. The global mass matrix $\left(\mathbf{M}_{G}\right)$ is constructed by assembling the matrices of the undamaged parts with those of the cracked regions.

\subsubsection{Damping matrix}

Proportional Rayleigh damping is used to construct the global damping matrix $\mathbf{C}_{G}$,

$$
\mathbf{C}_{G}=a_{0} \mathbf{M}_{G}+a_{1} \mathbf{K}_{G},
$$

where $a_{0}$ and $a_{1}$ are proportionality factors given by

$$
\left\{\begin{array}{l}
a_{0} \\
a_{1}
\end{array}\right\}=\frac{2 \zeta}{\omega_{m}+\omega_{n}}\left\{\begin{array}{c}
\omega_{m} \omega_{n} \\
1
\end{array}\right\},
$$

where $\zeta$ is the damping ratio taken as $5 \%$, and $\omega_{m}$ and $\omega_{n}$ are the angular frequencies.

In applying the proportional damping matrix, it is recommended in [27, Chapter 12] that $\omega_{m}$ and $\omega_{n}$ generally to be taken, respectively, as the un-damped fundamental frequency of the system and one of the 
higher frequencies of the modes that contribute significantly to the dynamic response. In the present study, and with the frequency range considered, $\omega_{m}$ is taken as the $1^{\text {st }}$ un-damped natural frequency and $\omega_{n}$ is set as the $4^{\text {th }}$ un-damped natural frequency.

Rayleigh damping is suitable for systems with non-linear responses due to changes in stiffness. It also considers contributions from higher modes due to the proportional combination of mass and stiffness matrices [27. Chapter 12].

\subsection{Material constitutive relationship}

The constitutive relationships illustrated in Fig. 4 are applied for concrete in tension. For the description of the equations of the stress-crack width relationship for each loading scenario, the reader may refer to the authors' work [18.

[Figure 4 about here.]

For concrete in compression the constitutive law presented in Fig. 5 is applied. This is because in RC beams compressive stresses start to behave non-linearly at early stages of damage.

[Figure 5 about here.]

When loading is applied, the constitutive model developed by Sima et al. 28, is adopted by modifying it to a stress-elongation relationship. First, concrete behaves linearly up to half of the ultimate compressive strength, where Eq. (9) applies. After that, the stress-elongation relationship behaves exponentially as,

$$
f_{c}=\left(\nu_{o}(1-A)+A \nu_{c} \exp \left(\frac{\left(\nu_{o}-\nu_{c}\right)}{\nu_{c u}}\right)\right) E_{c}
$$

where $f_{c}$ is the concrete stress, $\nu_{o}$ is the elongation at the linear-elastic state, $\nu_{c}$ is the concrete elongation, $\nu_{c u}$ is the elongation at the ultimate compressive strength taken as $0.002 h_{c}$ and $A$ is obtained from

$$
A=\frac{\left(f_{c u}-\nu_{o} E_{c}\right)}{E_{c}\left(\nu_{c u} \exp \left(\frac{\nu_{o}}{\nu_{c u}}-1\right)-1\right)} .
$$

If any unloading or reloading occurs in the linear-elastic state, the stress is calculated by

$$
f_{c}=\frac{E_{c} \nu_{c}}{h_{c}}
$$

However, if the model is loaded up to the exponential part of the loading envelope curve, the linear constitutive model proposed by Bai et al. [29] is applied for both unloading and reloading scenarios. The gradient of this linear constitutive model $\left(E_{c}^{\prime}\right)$ is obtained from,

$$
E_{c}^{\prime}=E_{c}\left(1-0.3\left(\frac{\nu_{e u}}{\nu_{c u}}\right)\right)
$$

which is used to calculate the stress in the reloading path using Eq. 9. The reloading continues linearly up to the envelope curve where thereafter Eq. (8) applies again. 
For the case of steel reinforcement, the constitutive relationship developed by Bai et al. [29], which ignores the Bauschinger effect, is adopted as shown in Fig. 6. In the loading scenario, the elastic region is followed by a plateau as described by

$$
\left.\begin{array}{c}
f_{s}=\frac{E_{s} \nu_{s}}{h_{c}} \quad \text { for } \nu_{s} \leq \nu_{y} \\
f_{s}=f_{y} \quad \text { for } \nu_{y}<\nu_{s}
\end{array}\right\},
$$

where $E_{s}$ is the Young's modulus of steel, $f_{s}$ is the steel stress, $\nu_{s}$ is the steel elongation, $f_{y}$ is the yield strength of steel and $\nu_{y}$ is the steel elongation at yield.

[Figure 6 about here.]

When steel elongation, due to loading state, falls in the elastic region, both unloading and reloading states follow the linear-elastic region. However, when unloading starts from a point in the yield plateau, unloading and reloading steel stress follows the bilinear model described by

$$
f_{s}=E_{s}\left(\frac{\nu_{s}-\nu_{p s}}{h_{c}}\right)
$$

in which $\nu_{p s}$ is the residual elongation for inclined path.

It must be noted that strong bond between concrete and steel is considered in the linear-elastic elements whereas bond is neglected in the cracked regions.

\subsection{Solution algorithm}

The dynamic behaviour of the model is scrutinised at different levels of damage. First, the model is subject to incremental static loading, applied as displacement in four-point bending, up to the required damage level. Then, the displacement is incrementally unloaded, where the unloading is continued to a negative value equal to $2 \%$ of the ultimate capacity of the beam model. This value is arbitrarily chosen so as to be larger than the response amplitude when the model is dynamically examined. The residual stiffness of each cracked region of the model is determined by fitting a cubic polynomial to its unloading moment-rotation curve about zero moment. This residual stiffness is related to the relative rotation of the cracked region in order to update the modified stiffness matrix $\left(\mathbf{K}_{m o d}\right)$ at each time step of the dynamic analysis. After that, the model is subject to sinusoidal excitations to study its dynamic behaviour.

This procedure is repeated for each load increment which is achieved by increasing the applied displacement. Fig. 7 shows a flowchart summarising the steps followed in conducting static and dynamic analysis with the model.

[Figure 7 about here.] 


\subsubsection{Static analysis}

The compatibility and equilibrium at the interface with the cracked region are ensured using a multi-variate Newton-Raphson iterative solver. From the global stiffness matrix of the RC beam model, an expression (G) relating together the unknown nodal displacements and rotations $\left(\mathbf{U}_{u n}\right)$, the applied displacements $\left(\mathbf{U}_{a p p}\right)$ and the external forces $\left(\mathbf{P}_{e x t}\right)$ is obtained,

$$
\mathbf{G}=\left[\mathbf{K}_{G}\right]_{u n} \mathbf{U}_{u n}+\left[\mathbf{K}_{G}\right]_{a p p} \mathbf{U}_{a p p}-\mathbf{P}_{\text {ext }} .
$$

The function $(\mathbf{G})$ is a vector with a length equal to the number of degrees of freedom of the model, where each element represents the residual force in each node. Therefore, in order to obtain equilibrium and compatibility, each element in the function should equal, or be close to, zero. This is achieved by using a multi-variate Newton-Raphson iterative solver where a successive solution approach is adopted.

When displacements are applied, the corresponding nodal displacements and rotations $\left(\mathbf{U}_{\text {corr }}\right)$ are calculated using

$$
\mathbf{U}_{\text {corr }}=\mathbf{U}_{u n}-\mathbf{J}^{-1} \mathbf{G}
$$

where the Jacobian matrix is taken initially as $\left[\mathbf{K}_{G}\right]_{u n}$, and it is then approximated numerically at each loading step, applying a central difference for Eq. 13.

As mentioned before, each cracked region is modelled in the same way as presented in [18. The relative rotation of each cracked region $(\phi)$ is computed from the corresponding rotations (Eq. (14)). From the relative rotation, the elongation at the bottom fibre $\left(\nu_{x}\right)$ is obtained and then utilised to calculate the deformation profile using the section geometry. Concrete stresses are calculated adopting the appropriate constitutive relationships (Figs. 4 and 5). For steel reinforcement, the elongations at the location of top and bottom bars are used to calculate steel stresses using the appropriate constitutive law (Fig. 6). The concrete and steel stresses are used to calculate the total force on the section $\left(F_{c}\right)$ which should be zero at equilibrium.

After ensuring equilibrium in each cracked region, the bending moments at the interfaces with the undamaged parts are obtained, and utilised together with the relative rotations to compute the modification factor $(\alpha)$. The modified stiffness matrices of the cracked regions are then computed and assembled with the matrices of the undamaged parts to construct the global stiffness matrix. After that, a new function using Eq. (13) is calculated. This process is repeated until equilibrium and compatibility are achieved with a certain range $\left( \pm 10^{-5} N\right)$. In the subsequent loading step, the nodal displacements and rotations and the modified stiffness matrices are used in the first iteration to calculate $\left(\mathbf{U}_{\text {corr }}\right)$, using Eq. (14).

\subsubsection{Dynamic analysis}

For the dynamic analysis, the equations of motion of the system are,

$$
\mathbf{M}_{G} \ddot{\mathbf{U}}+\mathbf{C}_{G} \dot{\mathbf{U}}+\mathbf{K}_{G} U=\mathbf{F}(t),
$$


in which $\ddot{\mathbf{U}}, \dot{\mathbf{U}}$ and $\mathbf{U}$ are the acceleration, velocity and displacement vectors respectively, and $\mathbf{F}(t)$ is the sinusoidal input force. These equations of motion are solved numerically using the built-in MATLAB routine ode23t solver. This solver implements the trapezoidal rule using a 'free' interpolant and it is suitable for moderately stiff problems.

The equations of motion are set up in order to be solved numerically as,

$$
\left\{\begin{array}{c}
\dot{\mathbf{u}}_{1} \\
\dot{\mathbf{u}}_{2}
\end{array}\right\}=\left[\begin{array}{cc}
\mathbf{I} & 0 \\
0 & \mathbf{M}_{G}
\end{array}\right]^{-1}\left[\begin{array}{cc}
\mathbf{I} & 0 \\
-\mathbf{K}_{G} & -\mathbf{C}_{G}
\end{array}\right]\left\{\begin{array}{l}
\mathbf{u}_{1} \\
\mathbf{u}_{2}
\end{array}\right\}+\left[\begin{array}{cc}
\mathbf{I} & 0 \\
0 & \mathbf{M}_{G}
\end{array}\right]^{-1}\left\{\begin{array}{c}
0 \\
\mathbf{F}(t)
\end{array}\right\}
$$

where $\dot{\mathbf{u}}_{1}, \dot{\mathbf{u}}_{2}, \mathbf{u}_{1}$ and $\mathbf{u}_{2}$ are the velocity and displacement vectors respectively, and $\mathbf{I}$ is the identity matrix.

Both global stiffness matrix and global damping matrix are calculated at each time step. This is because elements in the global stiffness matrix that represent the cracked regions are functions of the nodal rotations. The global damping matrix is, in turn, a function of the global stiffness matrix and mass matrix (Eq. (18)). A small time step $(0.0005 \mathrm{~s})$ is used throughout the analysis in order to achieve adequate accuracy. This time step is also suitable for the frequency ranges that are used in the dynamic simulation.

First, the system is subject to swept sine excitations in order to study changes in resonant frequency with increasing damage. The swept sine excitations are applied using a stepped approach where the system is excited initially from rest at a single excitation frequency. Then, the system is excited from its final condition of the previous case at a higher excitation frequency. This process is repeated until the frequency range of interest is covered. Second, the system is subject to a harmonic excitation of a frequency lower than its first natural frequency using different amplitudes. This is to study the appearance of super-harmonics in the frequency domain and restoring force-displacement relationship. The restoring force of the system is the summation of the damping force and the stiffness force, and the time history of internal restoring force can be computed from

$$
f(u, \dot{u})=F(t)-m \ddot{u}(t),
$$

where $f(u, \dot{u})$ is the internal restoring force of the system and $F(t)$ is the excitation force and $m \ddot{u}(t)$ is the inertial force. For a detailed description of the restoring force surfaces the reader may refer to [30, 31].

\section{Experimental work}

The experimental work comprised static and dynamic tests on three RC beams. The static tests involved applying loads in four-point bending, whereas the dynamic tests included exciting the beams with sinusoidal excitations and measuring the response at different locations for each damage level. In the following sections, a detailed description of the design of the specimens and experimental techniques are presented. 


\subsection{Specimen and material design}

The RC beams are $3 \mathrm{~m}$ long with a cross-section $(210 \times 130) \mathrm{mm}$, simply supported on heavy steel sections that are half round at the top and firmly fixed to the strong floor. On top of these supports, square plates $(200 \times 200 \times 20) \mathrm{mm}$ are placed with elastomeric pads $(180 \times 50 \times 25) \mathrm{mm}$ positioned in between the plates and the beam.

The beams are reinforced in tension using three $10 \mathrm{~mm}$ diameter bars, and in compression using $6 \mathrm{~mm}$ diameter bars to support the shear links (stirrups). There are 21 stirrups)in each beam, with a diameter of $6 \mathrm{~mm}$, vertically positioned and equally spaced at $135 \mathrm{~mm}$ centres along the beam.

Typically, with this geometry each beam has an ultimate moment capacity of about $22 \mathrm{kNm}$, corresponding to an applied load of $44 \mathrm{kN}$ ignoring the effect of self-weight. Fig. 8 shows the geometry of the beams and test set-up.

[Figure 8 about here.]

The mechanical properties of concrete for the three beams are shown in Table 1 . Beams BS-I and BS-II were cast on the same day and beam BS-III was cast separately.

[Table 1 about here.]

With regard to steel reinforcement, type-2 deformed bars were used for the tension reinforcement, whereas plain bars were adopted for both compression and shear reinforcement. The mechanical properties for both types of steel reinforcement are presented in Table 2 , where $f_{y}$ is the yield strength of steel reinforcement.

[Table 2 about here.]

The stiffness of the elastomeric pads was measured experimentally by testing them in compression. The tests were conducted using the Zwick/Roell universal testing machine. The loading was applied under

displacement control in a stepped approach were at each step there was holding time of 5sec. Fig. 9 depicts the load-displacement relationship from which the vertical stiffness is determined. It is seen that the load-displacement behaviour is influenced by the effects of creep that takes place at the holding time steps. However, the pad generally behaves in a linear manner and thus its stiffness can be approximated as $1.1 \times$ $10^{7} \mathrm{~N} / \mathrm{m}$.

[Figure 9 about here.]

\subsection{Experimental methodology and measurement techniques}

The static load was applied incrementally under load-control with a rate of $0.1 \mathrm{kN} / \mathrm{s}$ up to the failure load. The damage levels were defined as percentages of the anticipated failure load of the beams. The intention 
was to distribute the damage levels between the cracking load and the failure load, with more data on the zone of cracking loading up to about $40 \%$ of the failure load. The importance of this zone was demonstrated experimentally by Neild et al. [7] who reported that the non-linearity in the vibration response of cracked RC beams increases up to around $30 \%$ of the collapse load and then decreases in a reverse trend. Therefore, ten damage levels were examined; one before the application of loading, serving as a reference point, and other nine levels between the cracking load and the failure load. Table 3 illustrates the ten damage levels for beams BS-I, BS-II and BS-III as a percentage of the failure load, which is shown between brackets.

[Table 3 about here.]

The midspan displacement was measured using a linear variable differential transformer (LVDT). The development of cracking was monitored by the naked eye and the crack heights were measured using a ruler. The cracks were first marked during each load step and then measured after removing the damaging loads for safety reasons. The temperature was measured during the testing period using a thermocouple at 1 hr intervals. This is because the sensitivity of changes in vibration properties to temperature variations has been addressed in several studies 32,34 .

Dynamically, the beams were excited using an electromagnetic shaker connected at $1 \mathrm{~m}$ from the support (see, Fig. 8). The vibration response was measured, using accelerometers, at three locations; above the support, to monitor the behaviour of bearing pads, on the excitation position and at $1.5 \mathrm{~m}$ from the support.

Two types of signals were applied; swept sine and harmonic excitation. The swept signal was adopted for measurements of frequency response functions (FRFs), where the frequency was slowly but continuously varied between $1 \mathrm{~Hz}$ and $1000 \mathrm{~Hz}$ covering the first four natural frequencies of the system. The period of each signal sweep was two seconds whereas the total duration of the test was ten seconds. The harmonic excitation, which was run for ten seconds with a frequency of $30 \mathrm{~Hz}$ using 20 different amplitudes, was adopted in order to build the restoring force surfaces, and also examine the appearance of super-harmonics in the frequency domain response.

\subsection{Experimental results}

In this section, part of the experimental results are shown to support the methodology followed in validating the numerical model. The remaining experimental results are shown in the validation part in section 5 .

Fig. 10 shows the temperature variations over a period of 30 days. It can be seen that the level of variation in the temperature is small as it varies between $21^{\circ} \mathrm{C}$ and $25^{\circ} \mathrm{C}$. This level of variation would have a minimal effect on changes in the vibration properties of the tested beams. Xia et al. [35] highlighted that the $1^{\text {st }}$ and $2^{\text {nd }}$ resonant frequencies of a $\mathrm{RC}$ slab change by less than $2 \%$ and $3 \%$ respectively over a temperature variation of $10^{\circ} \mathrm{C}$. Based on this, it is therefore appropriate to attribute changes in vibration properties of the RC beams examined here only to damage.

[Figure 10 about here.] 
Before applying loads on the beams, swept sine excitations were performed to compute the FRFs $\left(H_{1}\right)$ for the undamaged beams. Prior to the calculation of the FRFs, the mean value and best-fit linear trend are removed from the response time history using the MATLAB function dtrend with breakpoints. The FRFs were calculated using the cross-spectral density of the input and output $\left(S_{f y}(\omega)\right)$ and the power-spectral density of the input $\left(S_{f f}(\omega)\right)$ to minimise noise effects from,

$$
H_{1}=\frac{S_{f y}}{S_{f f}}
$$

Both the cross-spectral and power-spectral densities were calculated using MATLAB functions cpsd and pwelch respectively. First, the signal is divided into a number of overlapping segments and a Hamming window is applied to each segment. After that, the spectral densities are computed for each windowed segment, where this process is repeated three times for three measured similar vibration signals to reduce effects of noise. As a further check for the reliability of the vibration output measurements, the coherence function $\left(\gamma^{2}\right)$ of the signal was evaluated.

Fig. 11 presents the FRF and the coherence function of beam BS-I before the application of load for the response of the $3^{\text {rd }}$ accelerometer $(1.5 \mathrm{~m})$. The first four resonant frequencies can be seen; at which the measurements are reliable as the corresponding coherence functions are larger than 0.9. However, at other frequencies at the troughs of the FRFs, the coherence functions are very low and reach almost zero at some frequencies. This is because at the troughs of the FRFs the response of the beam is relatively small and is therefore more sensitive to noise. There are some peaks between the first and second resonant frequencies which might be due to torsional vibration.

[Figure 11 about here.]

Typical FRFs and coherence functions were identified for beams BS-II and BS-III and the fundamental resonant frequencies were extracted using the peak-picking method. This was done after enhancing the frequency resolution using zero padding, i.e. appending zeros to the signal. Although this process affects the amplitude of the signal, it is the value of the frequency that is important in this analysis. Table 4 summarises the fundamental resonant frequencies of the RC beams before being subject to damaging loads.

[Table 4 about here.]

Fig. 12 shows the reduction in the four resonant frequencies with increasing damage for beams BS-I, BSII and BS-III normalised to the undamaged resonant frequency in Table 4 It can be observed that all four resonant frequencies experience similar reduction with increasing damage contrary to the belief that higher modes are more sensitive to damage [36]. This point was also observed experimentally by other researchers 32. Generally, all frequencies reduce by about $8 \%$ at the application of the first $35 \%$ of the failure load. However, up to this damage level, the resonant frequency of the $1^{\text {st }}$ mode decreases slightly more than that of the other modes. After that, the rate of reduction decreases up to near failure where all four resonant 
frequencies reduce by about $12 \%$. It is also seen that the reduction in the service load (30-70\% of the failure load) is small $(\sim 3 \%)$.

Since all resonant frequencies have similar sensitivity to damage, we can therefore consider only changes in the first resonant frequency in the analysis. This is practically advantageous as the measurement of lower modes is easier than that of higher modes.

[Figure 12 about here.]

The beams were also excited harmonically at $30 \mathrm{~Hz}$ using different excitation amplitudes. This is to investigate appearance of super-harmonics in the frequency domain response and also to extract changes in modal stiffness from the restoring surfaces. The velocity and displacement signals were integrated numerically using [37]:

$$
\left.\begin{array}{l}
\dot{u}_{i}=\dot{u}_{i-1}+\frac{\Delta t}{2}\left(\ddot{u}_{i}+\ddot{u}_{i-1}\right) \\
u_{i}=u_{i-1}+\frac{\Delta t}{2}\left(\dot{u}_{i}+\dot{u}_{i-1}\right)
\end{array}\right\},
$$

where the time step $\left(\Delta t=\frac{1}{f_{S}}\right)$, and initial velocity and displacement are taken as zero and $f_{S}$ is the sampling frequency. The displacement power spectral density is calculated using MATLAB function pwelch.

Fig. 13 presents typical power spectral density displacement response for beam BS-I at a damage level of $35 \%$. There are super-harmonics at integer multiples of the excitation frequency $(30 \mathrm{~Hz})$. The magnitude of these super-harmonics, however, is relatively small in contrast to that of the excitation frequency. Despite this, the amplitude of the $2^{\text {nd }}$ harmonic $(60 \mathrm{~Hz})$ is related to that of the excitation frequency in order to examine changes in non-linearity. This ratio is referred to here as non-linearity coefficient, which is calculated at each damage level and related to the damage loads and crack heights. These results are shown in section 5.

[Figure 13 about here.]

\section{Model simulation and validation}

In this section, the results of the static and dynamic simulation of the RC beam model are presented and validated against the experimental data. The mean of the mechanical properties of the $\mathrm{RC}$ beams in Tables 1 and 2 are used in the simulations of the beam model.

\subsection{Static simulation}

Fig. 14 shows the load-displacement curves of the first two load increments of beam BS-I and the RC beam model. In general, the model shows reasonable approximation for the bending behaviour. It captures the non-linear behaviour after the cracking load $(5 \mathrm{kN}-6 \mathrm{kN})$ and the softening of the unloading curves. However, 
the model shows smaller residual displacements than the beam, which could be due to neglecting the effects of the bond-slip. Both the beam and the RC beam model have slightly stiffer reloading curves than unloading curves. However, the area of the hysteresis in the unloading/reloading curve predicted by the model is greater than that of the beam.

[Figure 14 about here.]

The overall envelope load-displacement curves of the experiments and the RC beam model are presented in Fig. 15 The model generally compares well with the experimental data up to the cracking load ( $\sim 6 \mathrm{kN})$. Beyond the cracking load, the stiffness of the model is smaller than that of the experiments, which is attributed to the regular crack distribution in the model (see, Fig. 16. However, towards the failure load $(>40 \mathrm{kN})$, the model becomes stiffer than the experiments as it neglects the bond-slip behaviour.

[Figure 15 about here.]

Figs. 16 and 17 show the crack formation process in the beam model with increasing load by relating the crack height and the crack width of each cracked region to the position along the beam respectively. The crack height is measured from the bottom of the section up to the point at which the elongation in concrete exceeds the elongation at the ultimate tensile strength $\left(\nu_{c t}\right)$. The crack width is taken as the elongation at the bottom fibre $\left(\nu_{x}\right)$ minus $\nu_{c t}$. The crack heights and widths of symmetric cracked regions are equal at each loading step. It is interesting to note that, for cracked regions in the zone of pure bending $(1.08 \mathrm{~m}-1.62 \mathrm{~m})$, cracks occur concurrently and have the same height and width. This is theoretically true since the cracking moment in these cracked regions is equal, yet in reality cracks, in the pure bending zone, do not form simultaneously. This is a clear weakness in the model that could results in a softer behaviour in the dynamic analysis.

[Figure 16 about here.]

[Figure 17 about here.]

Fig. 18 presents typical cracking patterns in the tested beams, which were monitored by the naked eye and measured using a ruler. This may have led to missing cracks of small width, as at the $2^{\text {nd }}$ load increment no crack was visible, although the load-displacement curve is non-linear (see, Fig. 14). At the $3^{\text {rd }}$ load increment, three similar cracks appeared in the pure bending zone. The cracks distributed along the beam at almost regular spacings up to about $45 \%$ of the failure load, after which the rate of increase in crack heights reduced. After $60 \%$ of the failure load, small cracks initiated in between the principal cracks whose locations were governed by the shear link spacing. At failure, the height of the cracks around the midspan further increased and the bottom bars yielded.

[Figure 18 about here.] 
The average crack height, for beams BS-I and BS-II only, is calculated as a fraction of the overall depth of the beam at each damage level and plotted against load levels in Fig. 19. It is worth noting that the crack height was not recorded properly for beam BS-III and hence is not included in the analysis. The curves are contrasted with the estimation of the model for the average crack height. It can be seen that the model overestimates the average crack height in comparison to the beams by about $30 \%$ of the overall depth. This is due to the fact that the cracks in the beams were captured by the naked eye. The authors [18 found with the aid of digital image correlation techniques that cracks become visible to the naked eye when the width is more than $0.2 \mathrm{~mm}$. Hence, when this value is used to correct the model's prediction of the average crack height, the trend of increase in the average crack height is comparable. Between $15 \%$ and $45 \%$ of the failure load, there is a steep increase in the average crack height for both the model and the experimental data. After that, the average crack height gradually increased to about $50 \%$ of the overall depth of the beam. However, the model's predictions show that at $30 \%$ of the failure load the average crack height is almost half the overall depth of the beam. This may explain previous results of vibration measurements which revealed that resonant frequencies experience the greatest reduction in early stages of damage $(20 \%$ $-30 \%$ ) of the failure load [12]. The experimental results also indicate that visual inspection methods might lead to underestimation of the true crack height in structures.

[Figure 19 about here.]

In order to use the beam model for the simulation of the vibration behaviour of cracked RC beams, the residual stiffness of each cracked region is determined. This is obtained by fitting a cubic polynomial to the moment-rotation curves of the cracked regions about zero moment. Fig. 20a shows a typical momentrotation curve of the cracked region at the mid-span during the vibration cycle, where negative moments indicate hogging, i.e. partial crack closure. Fig. 20b relates the modification factor $(\alpha)$ in Eq. (3) to the relative rotation in order to update the stiffness matrix of the cracked region at each time step for the dynamic analysis. There is a non-linear relationship where the value of $\alpha$ increases with negative rotations. This implies that there is a stiffness recovery when the crack is partially closed.

[Figure 20 about here.]

\subsection{Dynamic simulation}

\subsubsection{Responses to swept-sine excitation}

As mentioned earlier, the swept sine excitations are performed using a stepped approach. The model is excited with frequencies ranging from $31 \mathrm{~Hz}$ to $57 \mathrm{~Hz}$ at a step of $0.04 \mathrm{~Hz}$. This range covers the first natural frequency of the model for undamaged and damaged states. At each excitation frequency, the Root Mean Square (RMS) of the displacement response at the position of excitation (1m from the support) is calculated. 
Fig. 21 shows the RMS displacement-frequency relationship for an undamaged case and a damaged case of the model. It illustrates that the model has a fundamental frequency of about $43.85 \mathrm{~Hz}$ for the undamaged case and that this frequency reduces by about $3.5 \%$ at a damage level of $24 \%$ of the failure load. The fundamental frequency is similar to the resonant frequency of the first mode of the RC beams (see, Table 4. It can also be noticed that the amplitude of the damaged case is higher than that of the undamaged case. This is because the system has a softening behaviour. The procedure presented in Fig. 21 is repeated for each damage level to extract the resonant frequency corresponding to the maximum RMS.

[Figure 21 about here.]

Fig. 22 compares changes in the first resonant frequency of the experiments with increasing damage against those predicted by the RC beam model. In Fig. 22a, the model's prediction for the reduction with the damage level compares well with the experiments as it falls within the statistical limits at most damage levels. However, in Fig $22 \mathrm{~b}$ the model's prediction for the reduction with the average crack height are less accurate but are still comparable. This is because, as mentioned before, the experimental evaluation of the crack height was not robust. In both figures, at lower damage levels the model shows less reduction in the resonant frequency than the experiments. This is because the model has a larger gradient for the loaddisplacement behaviour (see, Fig. 15). Close to failure, the model also slightly underestimates the reduction in the frequency as it neglects the bond-slip behaviour and as a result it has stiffer bending behaviour than the experiments (see, Fig. 15).

[Figure 22 about here.]

\subsubsection{Responses to harmonic excitation}

Fig. 23 shows changes in the level of non-linearity, estimated from the response in the frequency domain with increasing damage, for the experimental results and the RC beam model. The non-linearity coefficient, which is calculated from the response in the frequency domain (see, Fig. 13), is related to the damage level in Fig. 23a and the average crack height in Fig. 23b. It can be discerned that there is a significant scatter in the experimental results. However, by fitting a cubic polynomial to the data, the behaviour is comparable to that of the model. The non-linearity increases with the damage level until it reaches a maximum level at about $40 \%$ of the failure load. Thereafter, the non-linearity decreases gradually. The level of non-linearity of the experimental results is slightly higher than that predicted by the model.

[Figure 23 about here.]

The reason of such behaviour in Fig. 23 may be explained with the aid of the constitutive relationships (see, Fig. 44) and the distribution of cracks (see, Figs. 16 and 17). From the constitutive relationships, when the width of the crack is less than the critical crack width $\left(w_{c}\right)$ the non-linearity is more pronounced in the 
unloading paths, and reduces when the crack width is close to the critical value. From the distribution of cracks, at a damage level varying between $30 \%$ and $40 \%$, the cracks start to spread along the beam where the width of some of them is larger than the critical crack width $\left(w_{c}\right)$.

Fig. 24 shows the relationship between the restoring force and the dynamic response (displacement) at the point of excitation for different damage levels of the $\mathrm{RC}$ beam model. It is possible to observe the reduction in the gradient of the curve with increasing damage, and also that the curves do not overlap at any point apart from the origin. This is because the adopted crack model is a non-linear model which does not consider full crack closure. If the crack model was a bi-linear model the stiffness of the undamaged and the damaged beam at crack closure (positive displacement) would be equal. Qualitatively, this observation matches the hypothesis of previous researchers [26, 38] that cracks in RC beams do not fully close during vibration cycles.

[Figure 24 about here.]

To approximate the modal stiffness at each damage level, a cubic polynomial fit of the restoring forcedisplacement curve is used. This cubic polynomial is in the form $\left(a x^{3}+b x^{2}+c x+d\right)$, from which the modal stiffness is found by differentiating with respect to $x$ and substituting $(x=0)$. Hence, the modal stiffness is taken as the coefficient $(c)$.

The changes in modal stiffness of the experimental results and the RC beam model with increasing damage are presented in Fig. 25. The reduction in stiffness is related to the damage level in Fig. 25a and to the average crack height in Fig. 25b. It must be noted that the experimental restoring force is calculated from the known input excitation force and the inertia force where the modal mass is taken as half the overall mass. This is because the excitation frequency is less then the first fundamental frequency of the beams. It can be observed that the trend of changes in the modal stiffness resembles that of the resonant frequencies (see, Fig. 22). This is expected as the resonant frequency is a function of the modal stiffness of the system. However, the stiffness is more sensitive to damage than the resonant frequency as it drops, close to failure, by about $45 \%$. Though it slightly over-predicts the behaviour, the model agrees reasonably with the experimental data. This over-prediction is due to the idealised cracking process in the model which results in a softer behaviour (see, Fig. 16).

[Figure 25 about here.]

\subsubsection{Influence of support condition}

The stiffness of the vertical springs used in the simulation is $\left(k_{s}=1 \times 10^{7} \mathrm{~N} / \mathrm{m}\right)$, which is equal to the stiffness of the elastomeric pads and represent softer supports. To scrutinise the effects of the condition of supports on the changes in vibration characteristics, the stiffness of the vertical springs was increased to $\left(k_{s}=1 \times 10^{12} \mathrm{~N} / \mathrm{m}\right)$ so as to simulate stiffer supports. The prediction of the model for the reduction in 
resonant frequency and the modal stiffness along with changes in the level of non-linearity are simulated again and contrasted with those presented earlier for identical damage levels.

Fig. 26 compares the reduction in resonant frequency for softer and stiffer supports with increasing damage. Overall, the trend of both curves is similar, but with much more reduction for the system supported on stiffer supports. For this case, at a damage level of $90 \%$ of the failure load, the resonant frequency reduces to about $80 \%$ in contrast to a decrease to $90 \%$ for the case of the softer supports. It is also observed that after a $30 \%$ damage level, the difference between the two curves is about $9 \%$, and it remains almost constant with increasing damage.

[Figure 26 about here.]

Fig. 27 shows that the level of non-linearity for the system supported on stiffer supports is higher than that supported on softer supports, though again the two curves have similar trends. At about $20 \%$ damage level, the level of non-linearity for the system with stiffer supports is three times larger than that with softer supports. This difference then gradually decreases until it becomes around 1.5 times at a damage level of $90 \%$ of the failure load. This indicates that the effect of the supports condition is at its greatest when the system is lightly damaged, i.e. for damage levels between $20 \%$ and $40 \%$ of the failure load.

[Figure 27 about here.]

The last comparison conducted in this section is for the reduction in the modal stiffness with increasing damage. In Figure 28, it can be seen that the trend of reduction for the system with stiffer supports resembles that for the system with softer supports. However, the system with stiffer supports predicts more reduction, where its stiffness decreases by about $75 \%$ at the application of $90 \%$ of the failure load. Comparatively, the modal stiffness of the system with softer supports reduces by approximately $45 \%$ at the application of $90 \%$ of the failure load. It is also worth noting that the difference between the two systems remains almost steady after a damage level of $30 \%$ of the failure load.

[Figure 28 about here.]

These observations suggest that the stiffness of the support plays a dominant role in changes in the vibration properties of RC beams and also in their levels of non-linearities with increasing damage. This in turn implies that it is difficult to draw conclusions on the sensitivity of changes in the vibration properties to the presence of damage without taking into account the effects of boundary conditions.

\section{Conclusions}

This paper has presented a $\mathrm{RC}$ beam model with multiple-distributed flexural cracks to investigate the degradation in vibration characteristics of cracked $\mathrm{RC}$ beams. The model is subject to incremental static 
four-point bending while its dynamic behaviour is examined at each load increment using swept sine and harmonic excitations. The cracked regions are described by a modified stiffness matrix that its rotational stiffness is obtained from the FCM at each loading step. A multi-variate Newton-Raphson iterative solver is utilised, whereas the equations of motion are solved numerically using the built-in MATLAB routine ode23t.

The efficacy of the RC beam model is assessed against experimental results of RC beams under incremental static loading. The assessment includes comparisons of both static and dynamic simulations. The model in general compares reasonably well with the experimental data. In the static simulation, the model shows that visual monitoring of crack development may lead to underestimating the actual crack heights. This is indeed dependent on the definition of cracking which can either be based on the fictitious crack or on the visible crack.

In the dynamic simulation, the model reveals that there is a weak reduction in the resonant frequency with increasing damage and that most of this reduction occurs at the early stages of damage, i.e. up to $40 \%$ of the failure load. The level of non-linearity, which is discerned from the appearance of super-harmonics, is found to be at its greatest when the system is slightly damaged. From the restoring force-displacement curves, it is shown that cracks do not fully close across vibration cycles. The model predicts an overall reduction in the modal stiffness of about $45 \%$ of its initial value.

An interesting observation revealed by the model is the effect of the support conditions on the changes in the vibration properties. It is found that for stiffer supports more reduction in the resonant frequency and modal stiffness, and increase in the level of non-linearity are predicted. The observations also suggest that if the support stiffness changes for any reason flexural damage will be masked. Yet, this observation may not be applicable to long-span bridges since their fundamental frequency would not be influenced by the supports' stiffness.

However, although the model's predictions are quantitatively comparable with the experimental results, the are some weakness in the model that limit its applications. First, the derivation of the modified stiffness matrix (cracked regions) considers only bending behaviour and neglects shear effects. Second, the model adopts simplified damping model for simulating the damping behaviour in cracked RC beams. Besides that, the model adopts strong bond-slip behaviour of steel reinforcement at the undamaged parts and neglects the bond-slip behaviour at the cracked regions. But, when all is said, there remains the application of the proposed model in tackling the inverse problem, i.e., identifying the damage state of a structure from vibration measurements. In the inverse problem, the severity and location of damage of a given structure will be determined based on changes in non-linearity and reduction in modal stiffness.

\section{Acknowledgement}

The authors would like to acknowledge the Faculty of Engineering of the University of Nottingham for funding this research. 


\section{References}

[1] Abdel Wahab MM, De Roeck G. Damage detection in bridges using modal curvatures: Application to a real damage scenario. Journal of Sound and Vibration 1999; 226(2):217-235.

[2] Brownjohn JMW, Moyo P, Omenzetter P, Lu Y. Assessment of highway bridge upgrading by dynamic testing and finite-element model updating. Journal of Bridge Engineering 2003; 8(3):162-172.

[3] Haritos N, Owen JS. The use of vibration data for damage detection in bridges: A comparison of system identification and pattern recognition approaches. Structural Health Monitoring 2004; 3(2):141-163.

[4] Maas S, Zürbes A, Waldmann D, Waltering M, Bungard V, De Roeck G. Damage assessment of concrete structures through dynamic testing methods. part 2: Bridge tests. Engineering Structures 2012; 34:483 -494 .

[5] Cawley P, Adams RD. A vibration technique for non-destructive testing of fibre composite structures. Journal of Composite Materials 1979; 13:161-175.

[6] Van Den Abeele K, De Visscher J. Damage assessment in reinforced concrete using spectral and temporal nonlinear vibration techniques. Cement and Concrete Research 2000; 30(9):1453-1464.

[7] Neild SA, Williams MS, McFadden PD. Nonlinear vibration characteristics of damaged concrete beams. Journal of Structural Engineering 2003; 129(2):260-268.

[8] Zhu XQ, Law SS. Nonlinear characteristics of damaged reinforced concrete beam from Hilbert-Huang transform. Journal of Structural Engineering- ASCE 2007; 133(8):1186-1191.

[9] Abraham ONL, Brandon JA. The modelling of the opening and closure of a crack. Journal of Vibration and Acoustics 1995; 117(3A):370-377.

[10] Chondros TG, Dimarogonas AD, Yao J. Vibration of a beam with a breathing crack. Journal of Sound and Vibration 2001; 239(1):57-67.

[11] Bouboulas AS, Anifantis NK. Finite element modelling of a vibrating beam with a breathing crack: observations on crack detection. Structural Health Monitoring 2011; 10(2):131-145.

[12] Eccles BJ. The use of non-linear vibrations in the health monitoring of reinforced concrete structures. PhD Thesis, University of Nottingham 1999.

[13] Eccles BJ, Owen JS, Choo BS, Woodings MA. Non-linear vibrations of cracked reinforced concrete beams. The 4th European Conference on Structural Dynamics, Eurodyn 99, 1999. 
[14] Neild S, McFadden PD, Williams MS. A discrete model of a vibrating beam using a time-stepping approach. Journal of Sound and Vibration 2001; 239(1):99-121.

[15] Tan CM. Nonlinear vibrations of cracked reinforced concrete beams. PhD thesis, University of Nottingham 2003.

[16] Cheng SM, Swamidas ASJ, Wu XJ, Wallace W. Vibrational response of a beam with a breathing crack. Journal of Sound and Vibration 1999; 225(1):201-208.

[17] Stang H, Olesen J, Poulsen P, Dick-Nielsen L. On the application of cohesive crack modeling in cementitious materials. Materials and Structures 2007; 40(4):365-374.

[18] Hamad WI, Owen JS, Hussein MFM. An efficient approach of modelling the flexural cracking behaviour of un-notched plain concrete prisms subject to monotonic and cyclic loading. Engineering Structures $2013 ; \mathbf{5 1 : 3 6}-50$.

[19] Cornelissen HAW, Hordijk DA, Reinhardt HW. Experiments and theory for the application of fracture mechanics to normal and lightweight concrete. Fracture toughness and fracture energy of concrete, 1986; $565-575$.

[20] Hordijk DA. Tensile and tensile fatigue behaviour of concrete; experiments, modelling and analyses. Heron 1992; 37(1):3-77.

[21] Ulfkjaer JP, Krenk S, Brincker R. Analytical model for fictitious crack propagation in concrete beams. Journal of Engineering Mechanics 1995; 121(1):7-15.

[22] Iyengar SRKT, Raviraj S, Jayaram TN. Analysis of crack propagation in strain-softening beams. Engineering Fracture Mechanics 2002; 69(6):761-778.

[23] FIB. Structural concrete - textbook on behaviour, design and performance. Fib bulletin no 512009.

[24] Piyasena R, Loo YC, Fragomeni S. Determination of crack spacing and crack width in reinforced concrete beams. Structural Engineering and Mechanics- An International Journal 2003; 15(2):159-180.

[25] Fantilli AP, Ferretti D, Iori I, Vallini P. Flexural deformability of reinfoced concrete beams. Journal of Structural Engineering 1998; 124(9):1041-1049.

[26] Neild SA, Williams MS, McFadden PD. Non-linear behaviour of reinforced concrete beams under lowamplitude cyclic and vibration loads. Engineering Structures 2002; 24(6):707-718.

[27] Clough RW, Penzien J. Dymanics of structures. Computers and Structures, Inc.: Singapore, 2003.

[28] Sima JF, Roca P, Molins C. Cyclic constitutive model for concrete. Engineering Structures 2008; 30(3):695-706. 
[29] Bai ZZ, Au FTK, Kwan AKH. Complete nonlinear response of reinforced concrete beams under cyclic loading. The Structural Design of Tall and Special Buildings 2007; 16(2):107-130.

[30] Masri SF, Caughey TK. A nonparametric identification technique for nonlinear dynamic problems. Journal of Applied Mechanics 1979; 46:433-447.

[31] Hamad WI. Flexural crack modelling for vibration-based damage detection of reinforced concrete beams. PhD thesis, University of Nottingham 2012.

[32] Peeters B, Maeck J, De Roeck G. Vibration-based damage detection in civil engineering: excitation sources and temperature effects. Smart Materials and Structures 2001; 10(3):518-527.

[33] Deraemaeker A, Reynders E, Roeck GD, Kullaa J. Vibration-based structural health monitoring using output-only measurements under changing environment. Mechanical Systems and Signal Processing $2008 ; 22: 34-56$.

[34] Kim JT, Park JH, Lee BJ. Vibration-based damage monitoring in model plate-girder bridges under uncertain temperature conditions. Engineering Structures 2007; 29:1354-1365.

[35] Xia Y, Weng S, Su JZ, Xu YL. Temperature effect on variation of structural frequencies: from laboratory testing to field monitoring. The 6th International Workshop on Advanced Smart Materials and Smart Structures Technology, 2011.

[36] Fan W, Qiao P. Vibration-based damage identification methods: A review and comparative study. Structural Health Monitoring 2011; 10(1):83-111.

[37] Worden K, Tomlinson GR. Nonlinearity in structural dynamics: detection, identification and modelling. Institute of Physics Press, 2001.

[38] Maeck J. Damage assessment of civil engineering structures by vibration monitoring. PhD thesis, Katholieke Universiteit Leuven 2003.

\section{Appendix A}

This appendix describes the derivation of the modified stiffness matrix used to represent the cracked regions of the RC beam model. Starting from a beam element with a length of $h_{c}$ (Fig. 3), the derivation of the modified stiffness matrix is as follows:

(i) The behaviour of the beam element is divided into three cases as shown in Fig. 29

- Constant moment along the beam element, i.e. zero shear forces, which is the case for the cracked region at the section of symmetry. 
- Rotations at each end are equal and in the same direction, i.e. zero moment at the middle of the element.

- Relative displacements.

[Figure 29 about here.]

(ii) Now, from Fig. 29, the rotation and displacement at each end in Fig. 3 consist of

$$
\left.\begin{array}{c}
\phi_{1}=\psi_{1}+\psi_{2} \\
\phi_{2}=-\psi_{1}+\psi_{2} \\
\Delta_{1}=\delta_{1} \\
\Delta_{2}=\delta_{2}
\end{array}\right\}
$$

which can be re-arranged as,

$$
\left.\begin{array}{c}
\psi_{1}=\frac{\phi_{1}}{2}-\frac{\phi_{2}}{2} \\
\psi_{2}=\frac{\phi_{1}}{2}+\frac{\phi_{2}}{2} \\
\delta_{1}=\Delta_{1} \\
\delta_{2}=\Delta_{2}
\end{array}\right\}
$$

Eq. A.2 is written in a matrix form as,

$$
\left.\begin{array}{c}
\psi_{1}=\left[\begin{array}{llll}
0 & \frac{1}{2} & 0 & -\frac{1}{2}
\end{array}\right]\left[\begin{array}{c}
\Delta_{1} \\
\phi_{1} \\
\Delta_{2} \\
\phi_{2}
\end{array}\right], \quad \psi_{2}=\left[\begin{array}{llll}
0 & \frac{1}{2} & 0 & \frac{1}{2}
\end{array}\right]\left[\begin{array}{c}
\Delta_{1} \\
\phi_{1} \\
\Delta_{2} \\
\phi_{2}
\end{array}\right] \\
{\left[\begin{array}{l}
\delta_{1} \\
\delta_{2}
\end{array}\right]=\left[\begin{array}{llll}
1 & 0 & 0 & 0 \\
0 & 0 & 1 & 0
\end{array}\right]\left[\begin{array}{c}
\Delta_{1} \\
\phi_{1} \\
\Delta_{2} \\
\phi_{2}
\end{array}\right]}
\end{array}\right\} .
$$

(iii) Therefore, referring to Fig. 29 and Eqs. (2) and (A.3), matrices relating the end forces and moments are constructed for:

(a) constant moment,

$$
\left[\begin{array}{c}
F_{11} \\
M_{11} \\
F_{21} \\
M_{21}
\end{array}\right]=\left[\begin{array}{c}
0 \\
\alpha \\
0 \\
-\alpha
\end{array}\right] \psi_{1}=\left[\begin{array}{cccc}
0 & 0 & 0 & 0 \\
0 & \frac{\alpha}{2} & 0 & -\frac{\alpha}{2} \\
0 & 0 & 0 & 0 \\
0 & -\frac{\alpha}{2} & 0 & \frac{\alpha}{2}
\end{array}\right]\left[\begin{array}{c}
\Delta_{1} \\
\phi_{1} \\
\Delta_{2} \\
\phi_{2}
\end{array}\right],
$$

where $\alpha$ is a the modification factor of the elements corresponding to end moments and rotations. 
(b) for end rotations in the same direction, which allows using Euler-Bernoulli beam theory,

$$
\left[\begin{array}{l}
F_{12} \\
M_{12} \\
F_{22} \\
M_{22}
\end{array}\right]=\left[\begin{array}{c}
\frac{12 E_{c} I_{c}}{h_{c}^{2}} \\
\frac{6 E_{c} I_{c}}{h_{c}} \\
-\frac{12 E_{c} I_{c}}{h_{c}^{2}} \\
\frac{6 E_{c} I_{c}}{h_{c}}
\end{array}\right] \psi_{2}=\left[\begin{array}{cccc}
0 & \frac{6 E_{c} I_{c}}{h_{c}^{2}} & 0 & \frac{6 E_{c} I_{c}}{h_{c}^{2}} \\
0 & \frac{3 E_{c} I_{c}}{h_{c}} & 0 & \frac{3 E_{c} I_{c}}{h_{c}} \\
0 & -\frac{6 E_{c} I_{c}}{h_{c}^{2}} & 0 & -\frac{6 E_{c} I_{c}}{h_{c}^{2}} \\
0 & \frac{3 E_{c} I_{c}}{h_{c}} & 0 & \frac{3 E_{c} I_{c}}{h_{c}}
\end{array}\right]\left[\begin{array}{c}
\Delta_{1} \\
\phi_{1} \\
\Delta_{2} \\
\phi_{2}
\end{array}\right]
$$

(c) for relative displacements, which allow using Euler-Bernoulli beam theory,

$$
\left[\begin{array}{l}
F_{13} \\
M_{13} \\
F_{23} \\
M_{23}
\end{array}\right]=\left[\begin{array}{cc}
\frac{12 E_{c} I_{c}}{h_{c}^{3}} & -\frac{12 E_{c} I_{c}}{h_{c}^{3}} \\
\frac{6 E_{c} I_{c}}{h_{c}^{2}} & -\frac{6 E_{c} I_{c}}{h_{c}^{2}} \\
-\frac{12 E_{c} I_{c}}{h_{c}^{3}} & \frac{12 E_{c} I_{c}}{h_{c}^{3}} \\
\frac{6 E_{c} I_{c}}{h_{c}^{2}} & -\frac{6 E_{c} I_{c}}{h_{c}^{2}}
\end{array}\right]\left[\begin{array}{l}
\delta_{1} \\
\delta_{2}
\end{array}\right]=\left[\begin{array}{cccc}
\frac{12 E_{c} I_{c}}{h_{c}^{3}} & 0 & -\frac{12 E_{c} I_{c}}{h_{c}^{3}} & 0 \\
\frac{6 E_{c} I_{c}}{h_{c}^{2}} & 0 & -\frac{6 E_{c} I_{c}}{h_{c}^{2}} & 0 \\
-\frac{12 E_{c} I_{c}}{h_{c}^{3}} & 0 & \frac{12 E_{c} I_{c}}{h_{c}^{3}} & 0 \\
\frac{6 E_{c} I_{c}}{h_{c}^{2}} & 0 & -\frac{6 E_{c} I_{c}}{h_{c}^{2}} & 0
\end{array}\right]\left[\begin{array}{c}
\Delta_{1} \\
\phi_{1} \\
\Delta_{2} \\
\phi_{2}
\end{array}\right] .
$$

In these matrices, the first subscript corresponds to the end of the beam element and the second subscript corresponds to the case.

(iv) Now, by assembling the three cases in Eqs. A.4 A.6 together, a modified stiffness matrix $\left(\mathbf{K}_{m o d}\right)$ relating the end forces to the end rotations and displacements reads

$$
\mathbf{K}_{\text {mod }}=\left[\begin{array}{cccc}
\frac{12 E_{c} I_{c}}{h_{c}^{3}} & \frac{6 E_{c} I_{c}}{h_{c}^{2}} & -\frac{12 E_{c} I_{c}}{h_{c}^{3}} & \frac{6 E_{c} I_{c}}{h_{c}^{2}} \\
\frac{6 E_{c} I_{c}}{h_{c}^{2}} & \frac{3 E_{c} I_{c}}{h_{c}}+\frac{\alpha}{2} & -\frac{6 E_{c} I_{c}}{h_{c}^{2}} & \frac{3 E_{c} I_{c}}{h_{c}}-\frac{\alpha}{2} \\
-\frac{12 E_{c} I_{c}}{h_{c}^{3}} & -\frac{6 E_{c} I_{c}}{h_{c}^{2}} & \frac{12 E_{c} I_{c}}{h_{c}^{3}} & -\frac{6 E_{c} I_{c}}{h_{c}^{2}} \\
\frac{6 E_{c} I_{c}}{h_{c}^{2}} & \frac{3 E_{c} I_{c}}{h_{c}}-\frac{\alpha}{2} & -\frac{6 E_{c} I_{c}}{h_{c}^{2}} & \frac{3 E_{c} I_{c}}{h_{c}}+\frac{\alpha}{2}
\end{array}\right] .
$$

In the first loading step $\alpha=\frac{2 E_{c} I_{c}}{h_{c}}$ and thereafter $\alpha$ is calculated from the moment and interface rotation of the cracked region assuming constant moment along the region. By substituting the initial value of $\alpha$, Eq. A.7 is identical to Eq. 2. 


\section{List of Figures}

1 Cohesive stress distribution ahead of a visible crack. The symbols are defined in the

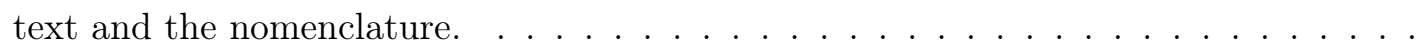

2 RC beam model layout. The length of the cracked regions is $h_{c}$ while the length of the undamaged parts in between the cracks is $l_{2}$ and that of those near the supports

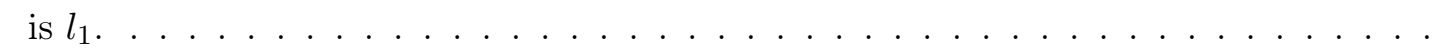

$3 \quad$ Beam element with end forces and moments.

$4 \quad$ Loading, unloading and reloading stress-elongation relationship for concrete in tension.

5 Loading, unloading and reloading stress-elongation relationship for RC in compres-

sion. $f_{o}$ is the concrete stress at the linear-elastic state. . . . . . . . . . . . .

$6 \quad$ Loading, unloading and reloading stress-elongation relationship for steel. .

$7 \quad$ Flowchart of the static and dynamic analysis using the RC beam model.

8 RC beam geometry and test set-up (all dimensions are in $\mathrm{mm}, 20 \mathrm{~mm}$ cover to reinforcement).

9 Load-displacement relationship for the elastomeric pad.

10 Typical temperature variations measured using a thermocouple over a period of 30 days at 1 hr intervals. .

11 Response of beam BS-I to a swept signal: (a) FRF (b) coherence function of the signal.

12 Reduction in resonant frequencies with damage level for beams: (a) BS-I (b) BS-II

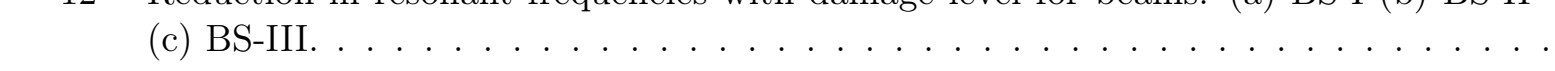

13 Power-spectral density of the displacement response for beam BS-I at a damage level of $35 \%$ due to a harmonic excitation of $30 \mathrm{~Hz} . \ldots \ldots \ldots \ldots$

14 Load-midspan displacement curves of two load increments for the RC beam model

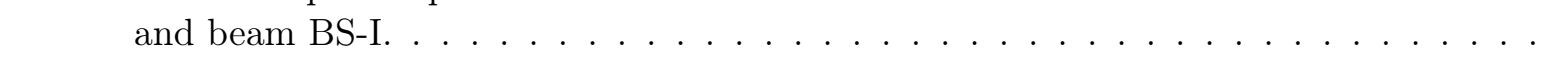

15 Comparison of load-midspan displacement curves between experiments and the RC beam model. . . . . . . . . . . . . . . . . . . .

16 Distribution of cracks along the RC beam model- crack height measured from the bottom of the section up to the point at which the elongation in concrete exceeds $\nu_{c t}$.

17 Distribution of cracks along the RC beam model- crack width taken as $\left(\nu_{x}\right)$ minus $\nu_{c t}$.

18 Typical crack development for RC beams under incremental static loading, ( - ) principal cracks $(\cdots)$ small cracks. $\ldots \ldots \ldots \ldots \ldots \ldots$

19 Comparison of average crack height with damage level between experiments and RC beam model. The model's predictions are modified by $0.2 \mathrm{~mm}$ in order to take into account the effect of monitoring crack development with the naked eye.

20 Typical prediction of the RC beam model for: (a) moment-rotation curve during a vibration cycle (b) $\alpha$-rotation curve during a vibration cycle. . . . . . . . . . . .

21 Response of the RC beam model to a swept sine excitation for an undamaged case and a damaged case. . . . . . . . . . . . . . . . . .

22 Comparison of reduction in resonant frequencies between experiments and RC beam

model: (a) reduction with damage level (b) reduction with average crack height. . . .

23 Comparison of changes in non-linearity between experiments and RC beam model:

(a) changes with damage level (b) changes with average crack height.

24 Restoring force-displacement curves for the RC beam model at different damage levels.

25 Comparisons of reduction in modal stiffness between experiments and RC beam

model: (a) reduction with damage level (b) reduction with average crack height. . . .

26 Comparison of reduction in resonant frequency for two types of supports of the RC beam model. 
27 Comparison of changes in non-linearity with damage level for two types of supports of the RC beam model. . . . . . . . . . . . . . . . . . . . . . .

28 Comparison of reduction in modal stiffness with damage level for two types of supports of the RC beam model. . . . . . . . . . . . . . . . . . .

29 Beam element cases: (a) constant moment (b) end rotations (c) relative displacements. 


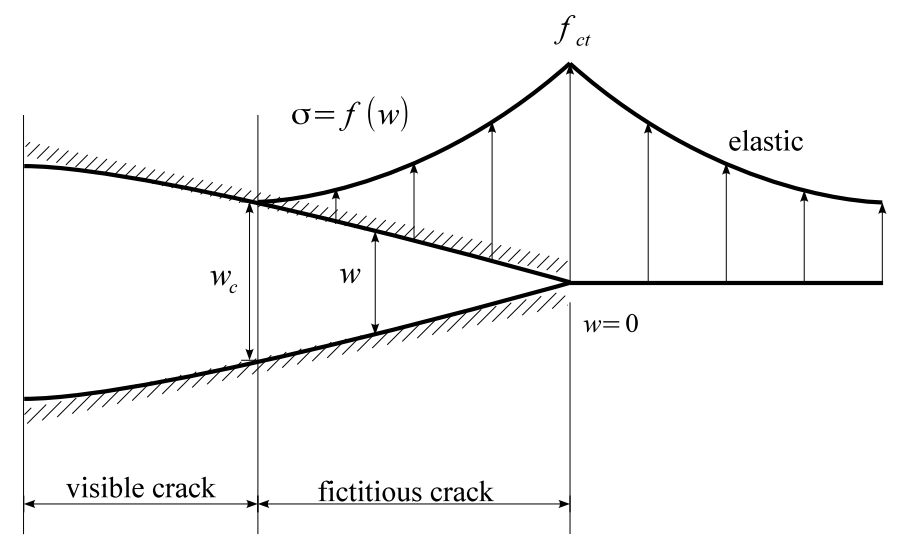

Figure 1: Cohesive stress distribution ahead of a visible crack. The symbols are defined in the text and the nomenclature. 


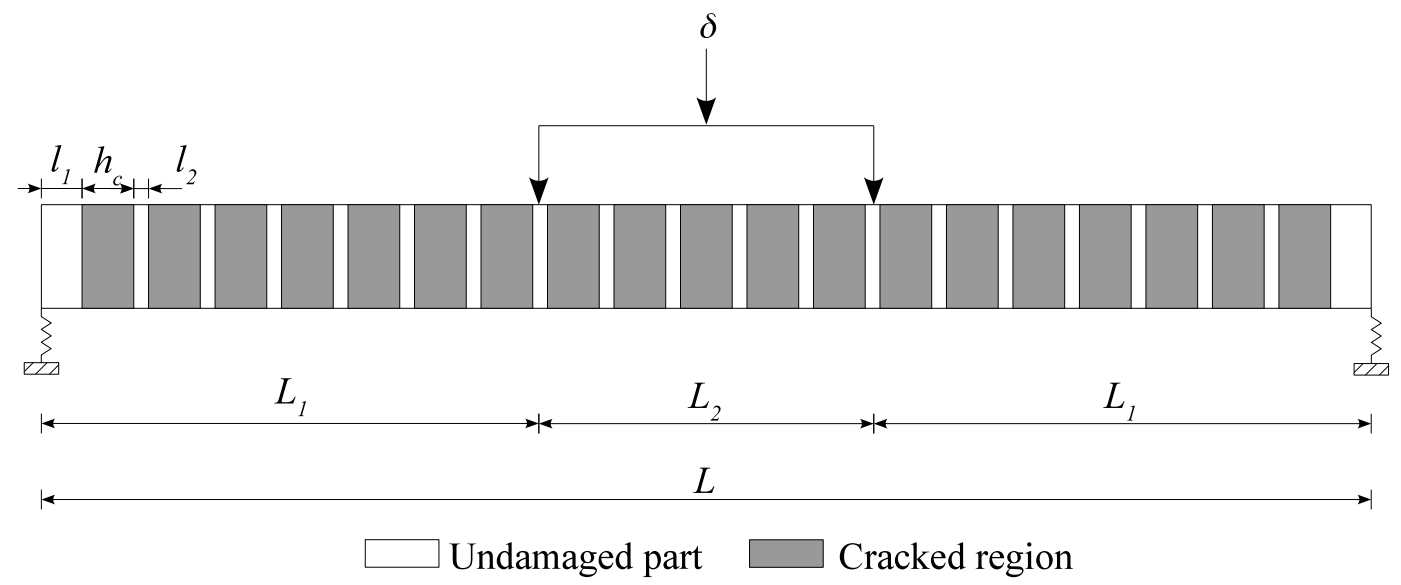

Figure 2: RC beam model layout. The length of the cracked regions is $h_{c}$ while the length of the undamaged parts in between the cracks is $l_{2}$ and that of those near the supports is $l_{1}$. 


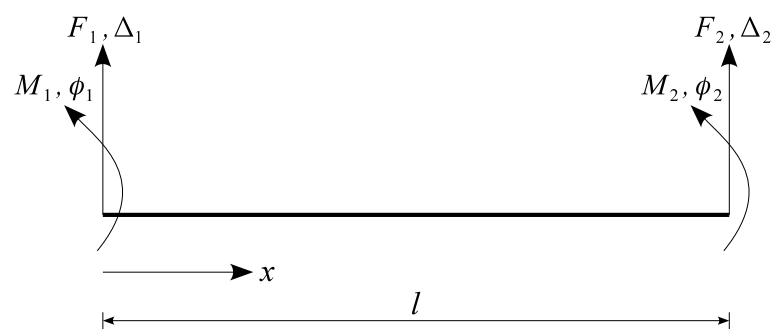

Figure 3: Beam element with end forces and moments. 


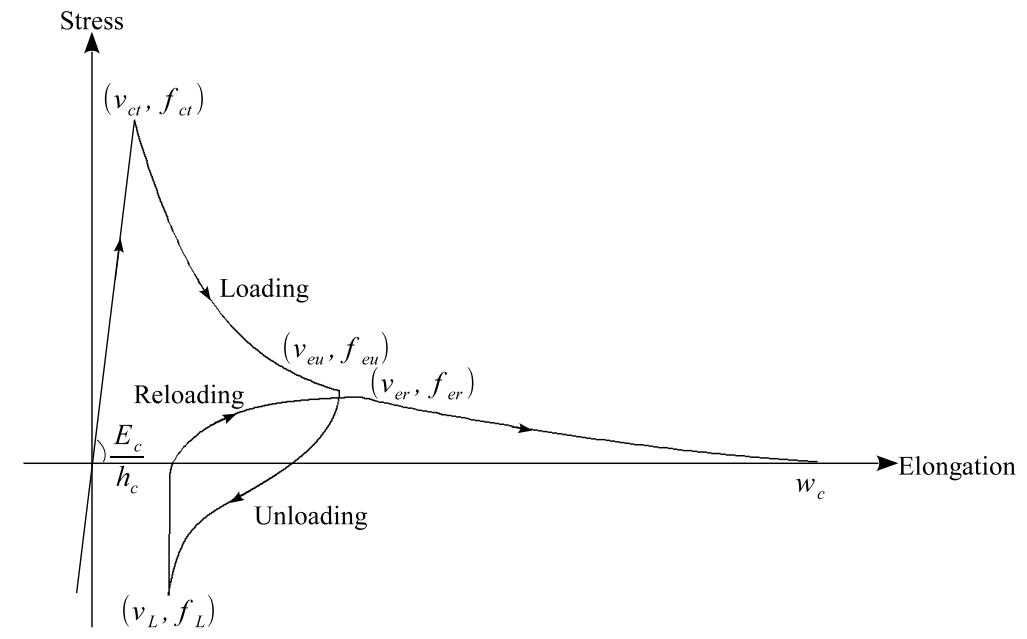

Figure 4: Loading, unloading and reloading stress-elongation relationship for concrete in tension. 


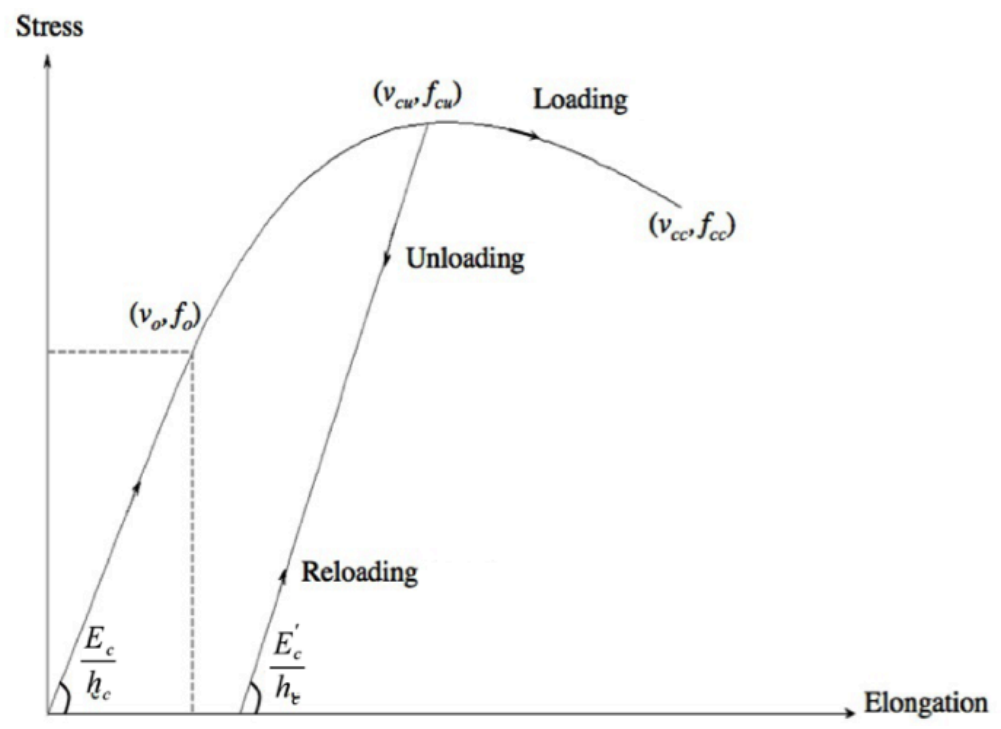

Figure 5: Loading, unloading and reloading stress-elongation relationship for RC in compression. $f_{o}$ is the concrete stress at the linear-elastic state. 


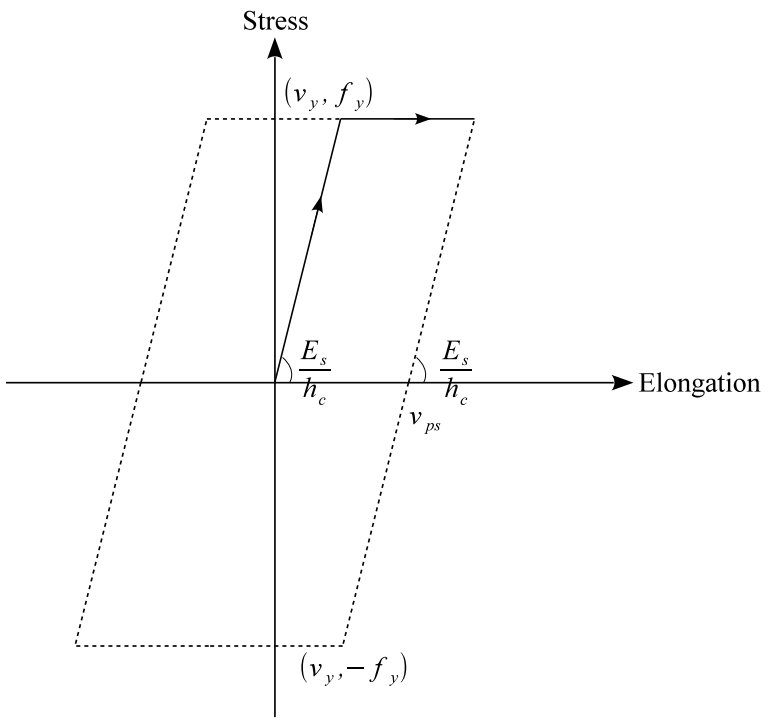

Figure 6: Loading, unloading and reloading stress-elongation relationship for steel. 


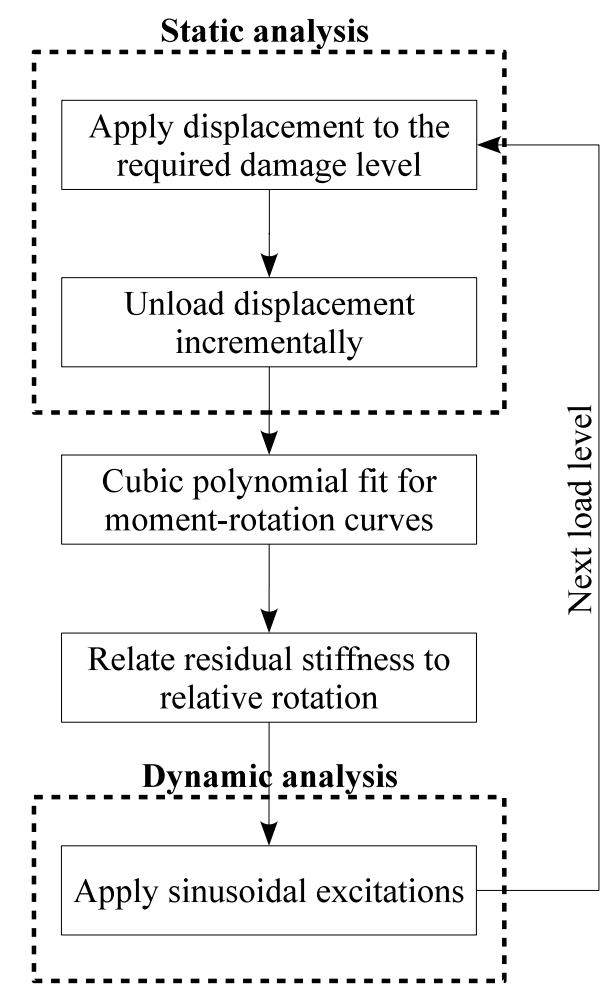

Figure 7: Flowchart of the static and dynamic analysis using the RC beam model. 


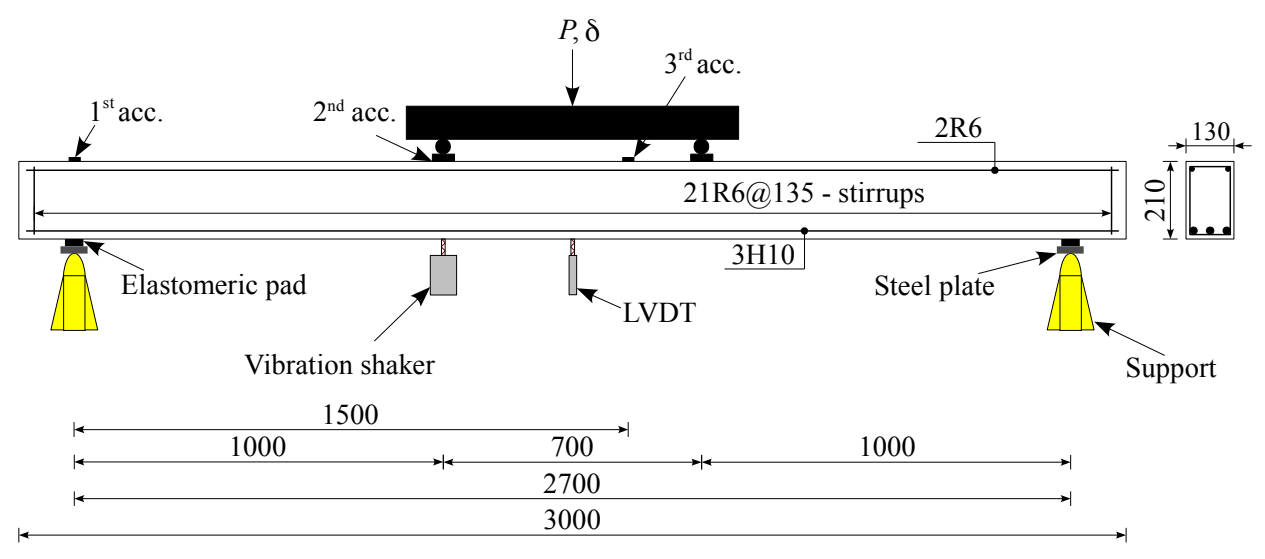

Figure 8: RC beam geometry and test set-up (all dimensions are in $\mathrm{mm}, 20 \mathrm{~mm}$ cover to reinforcement). 


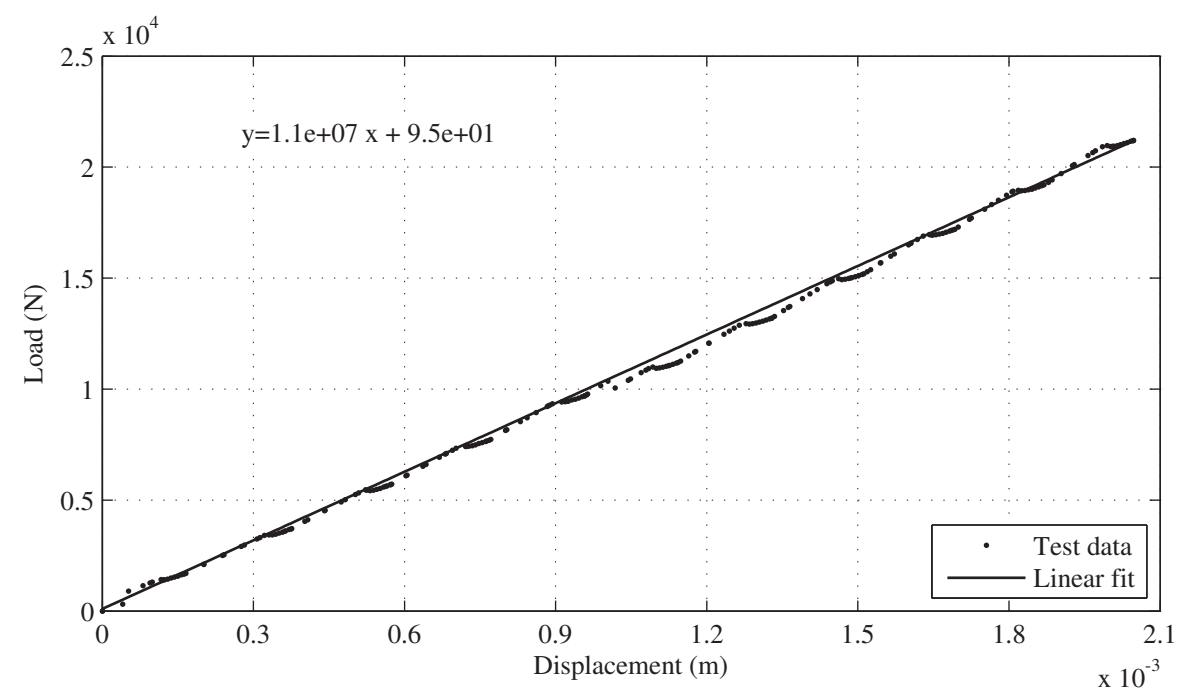

Figure 9: Load-displacement relationship for the elastomeric pad. 


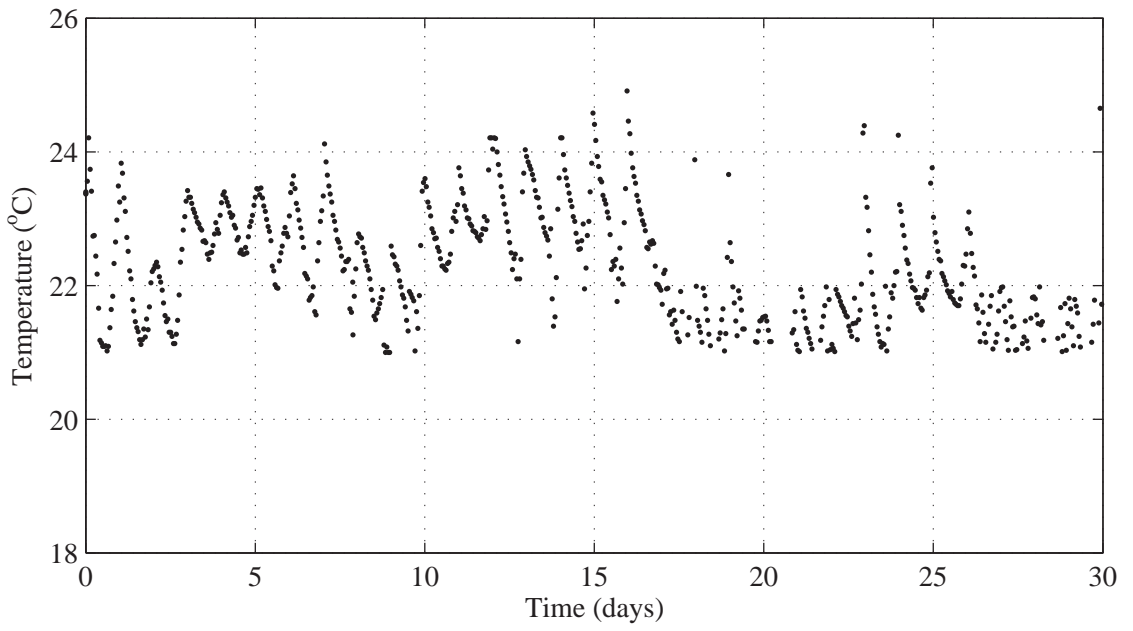

Figure 10: Typical temperature variations measured using a thermocouple over a period of 30 days at $1 \mathrm{hr}$ intervals. 
(a)

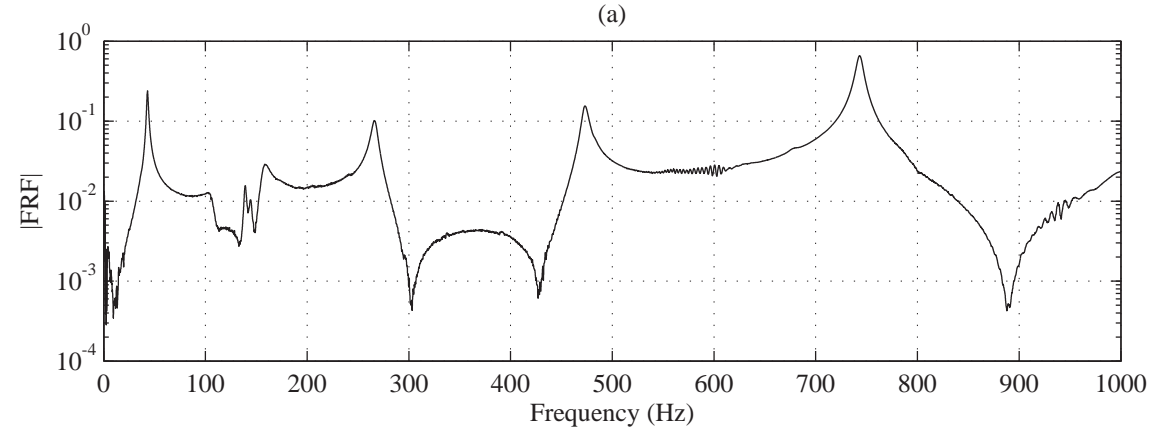

(b)

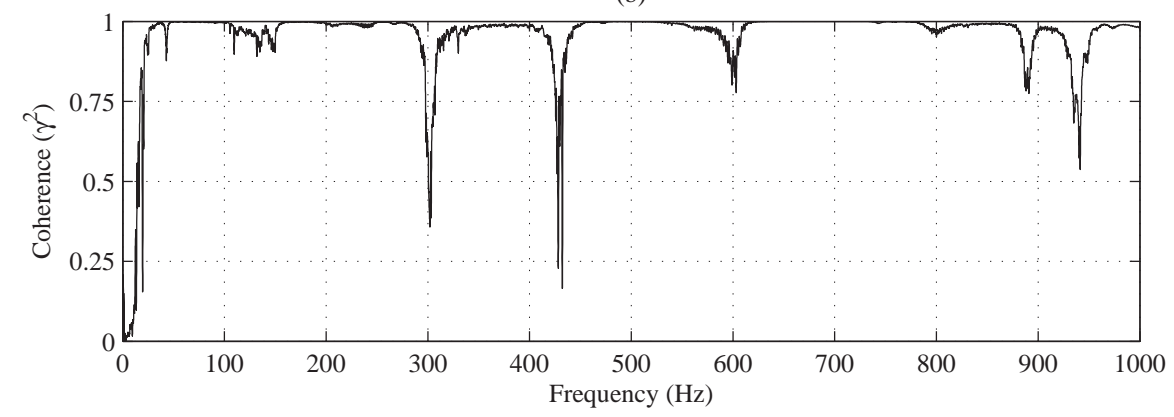

Figure 11: Response of beam BS-I to a swept signal: (a) FRF (b) coherence function of the signal. 
(a)

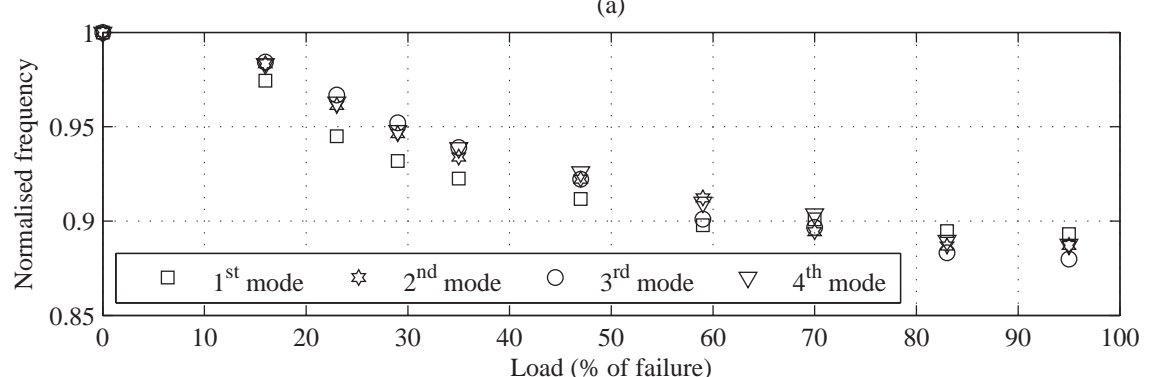

(b)

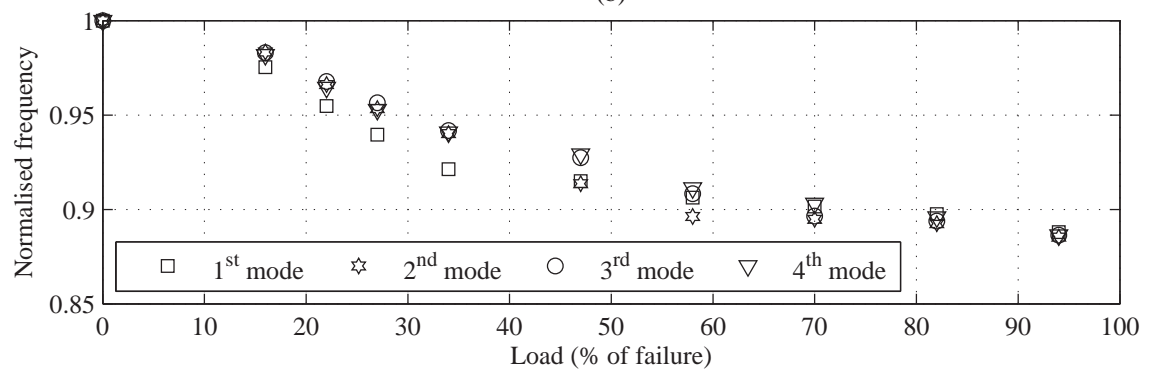

(c)

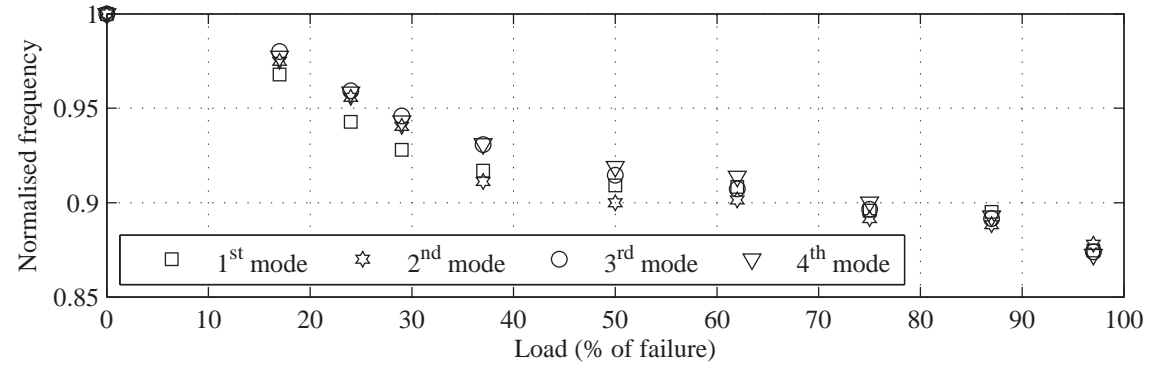

Figure 12: Reduction in resonant frequencies with damage level for beams: (a) BS-I (b) BS-II (c) BS-III. 


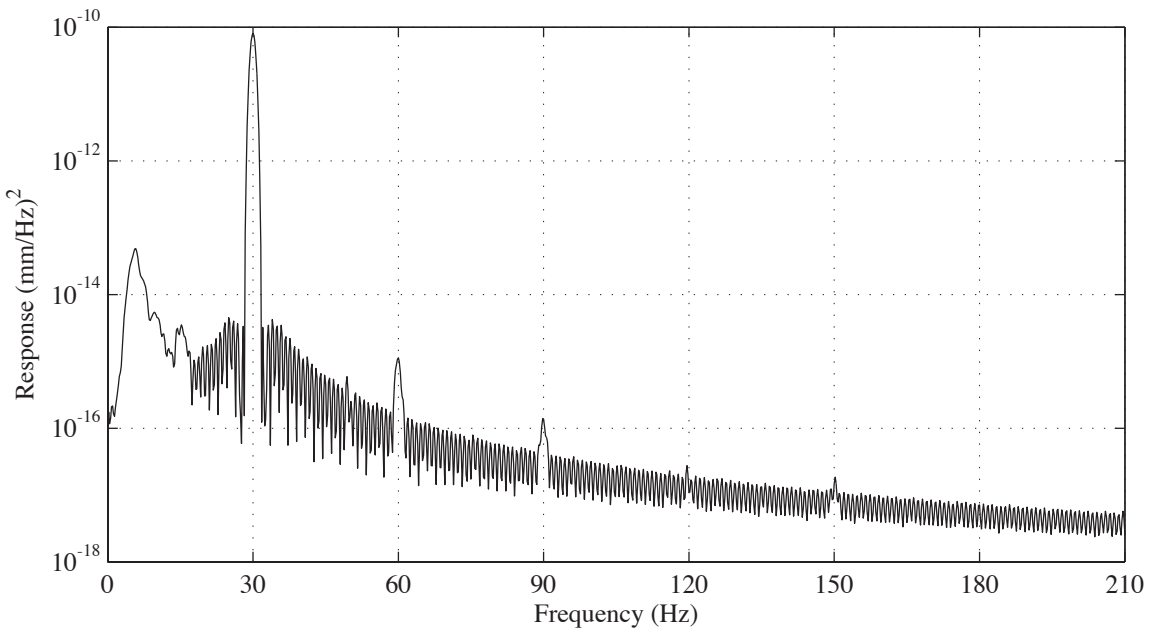

Figure 13: Power-spectral density of the displacement response for beam BS-I at a damage level of $35 \%$ due to a harmonic excitation of $30 \mathrm{~Hz}$. 


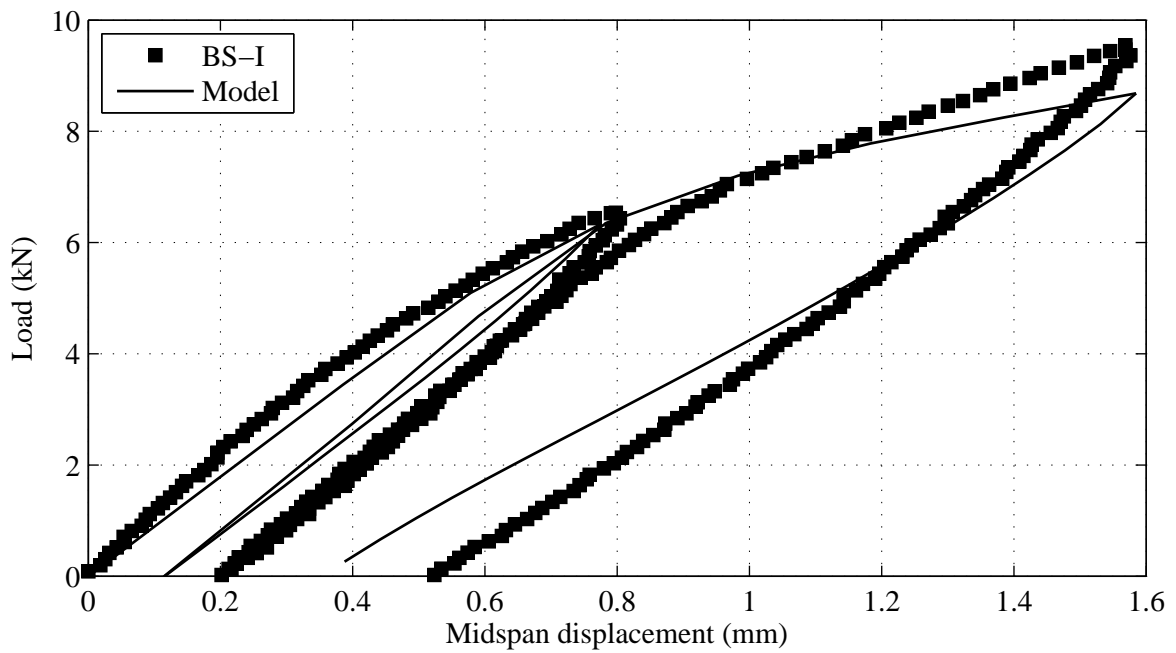

Figure 14: Load-midspan displacement curves of two load increments for the RC beam model and beam BS-I. 


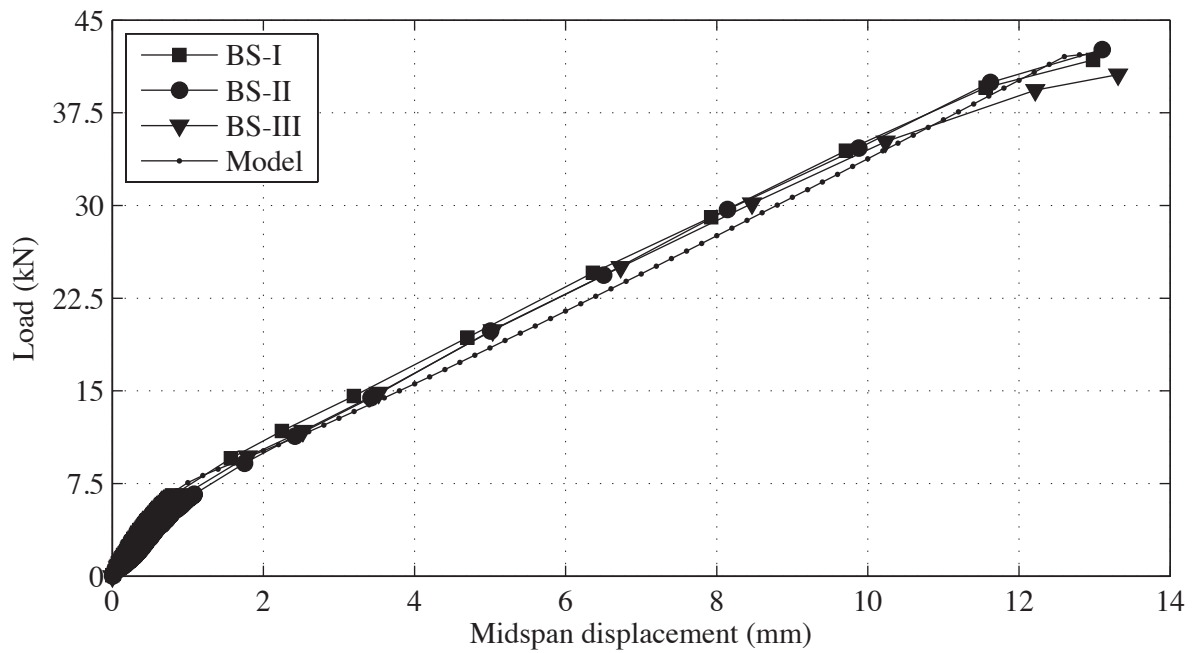

Figure 15: Comparison of load-midspan displacement curves between experiments and the RC beam model. 


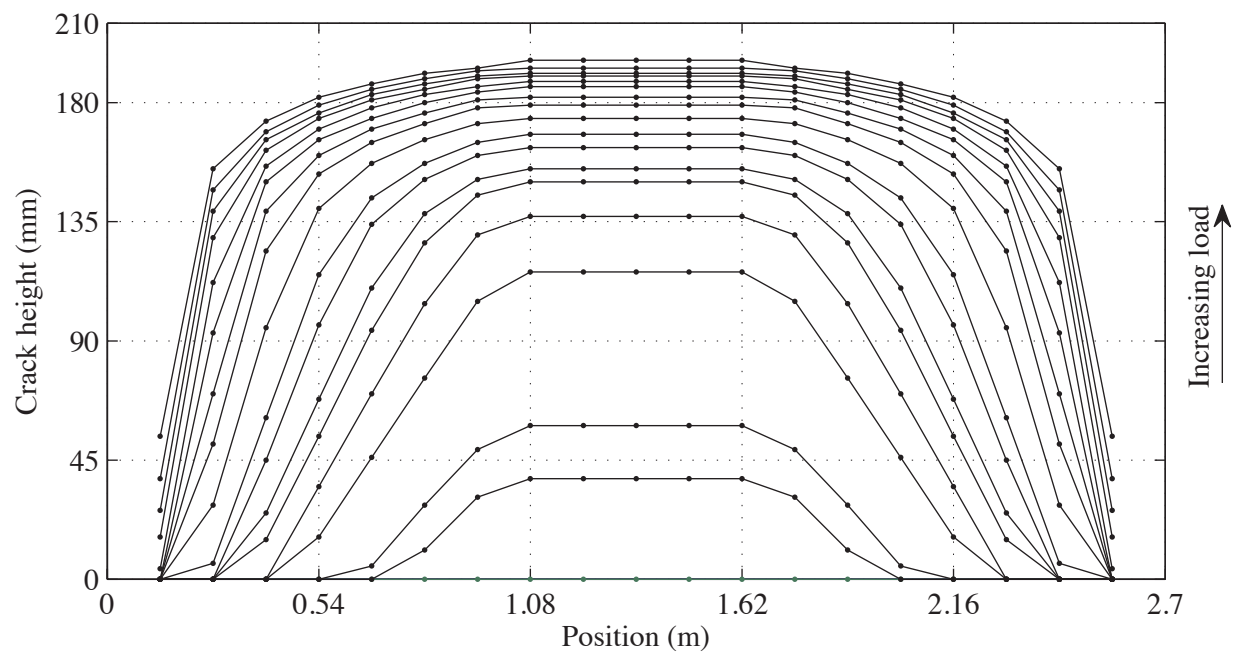

Figure 16: Distribution of cracks along the RC beam model- crack height measured from the bottom of the section up to the point at which the elongation in concrete exceeds $\nu_{c t}$. 


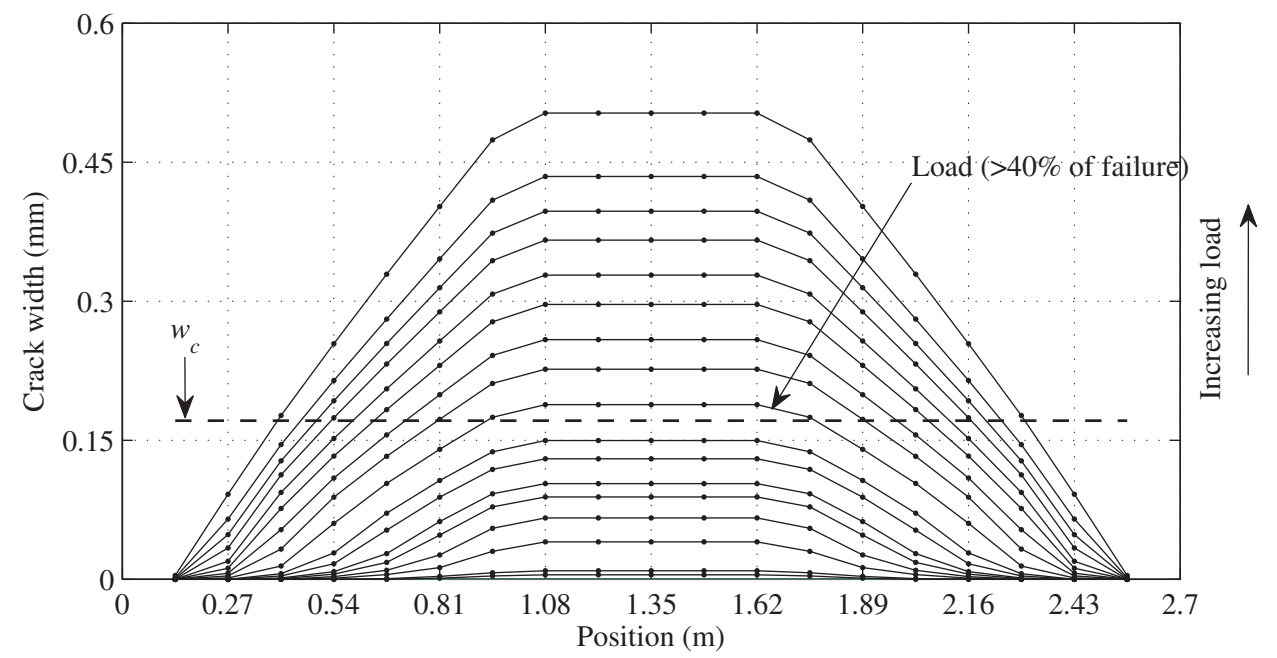

Figure 17: Distribution of cracks along the RC beam model- crack width taken as $\left(\nu_{x}\right)$ minus $\nu_{c t}$. 


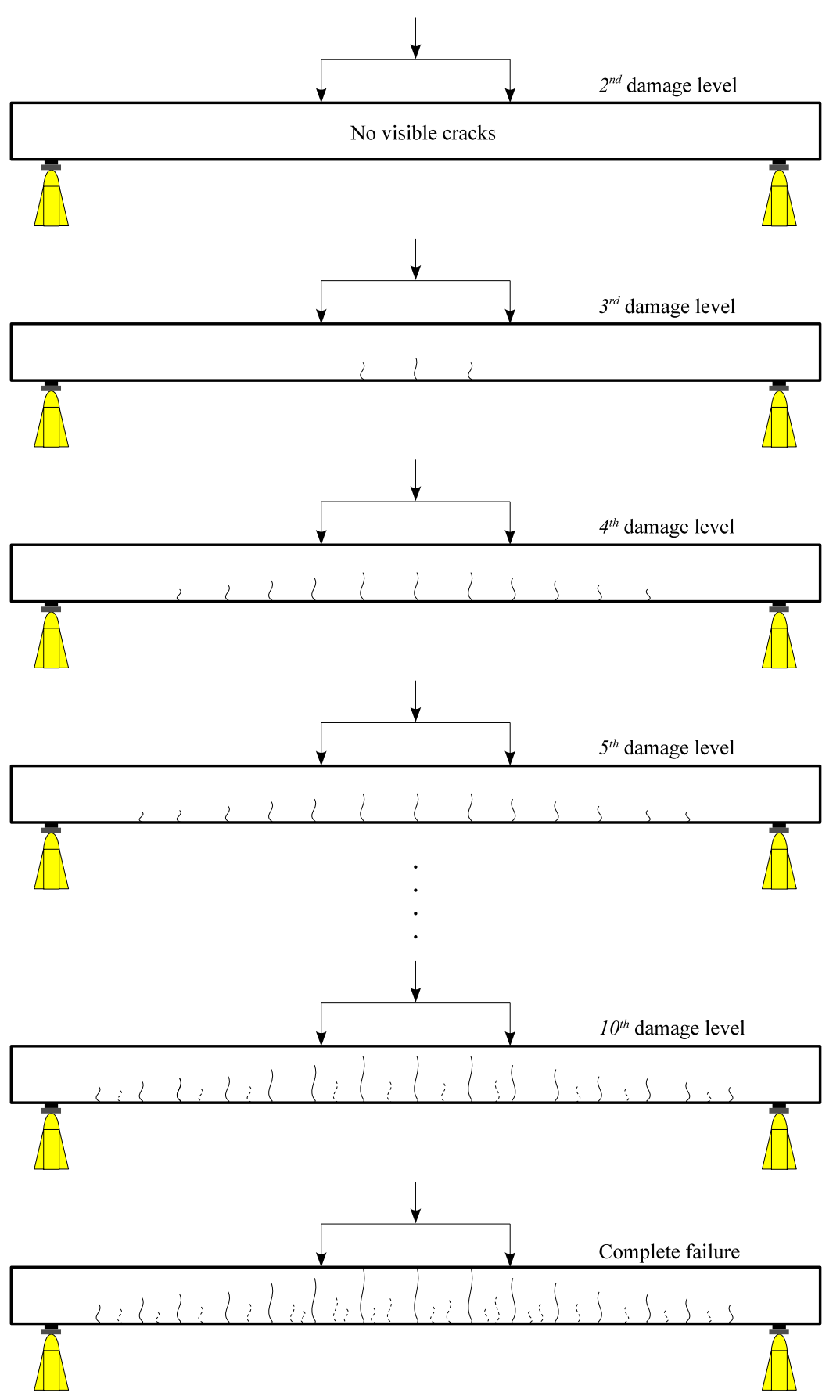

Figure 18: Typical crack development for RC beams under incremental static loading, (-) principal cracks $(\cdots)$ small cracks. 


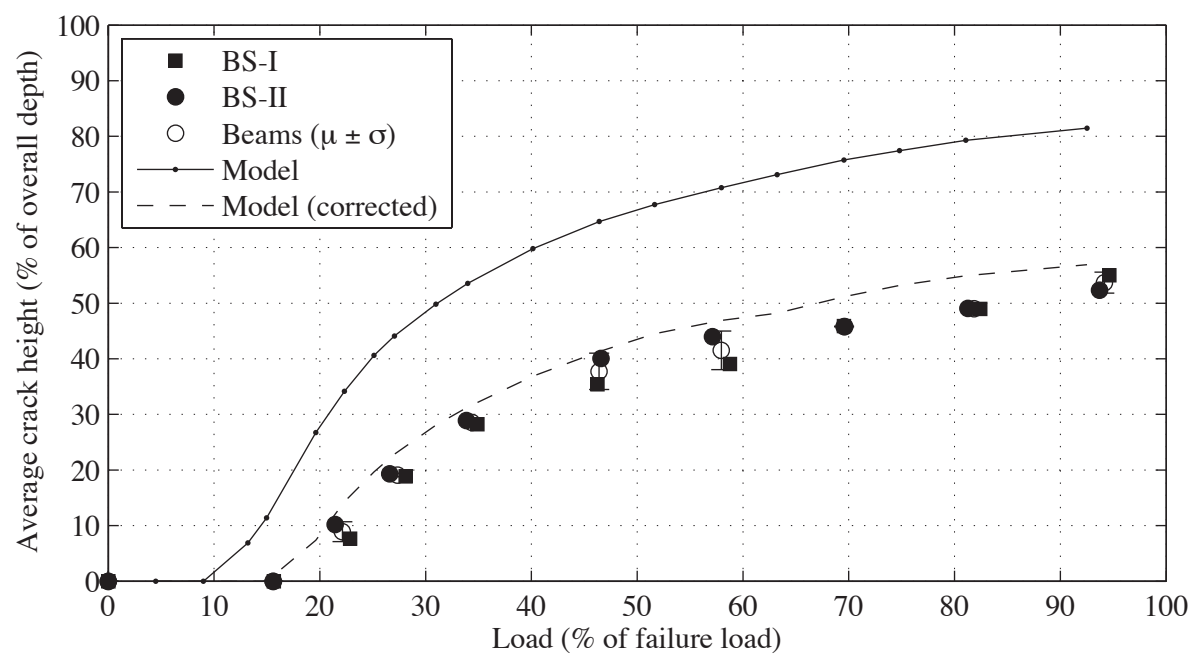

Figure 19: Comparison of average crack height with damage level between experiments and RC beam model. The model's predictions are modified by $0.2 \mathrm{~mm}$ in order to take into account the effect of monitoring crack development with the naked eye. 


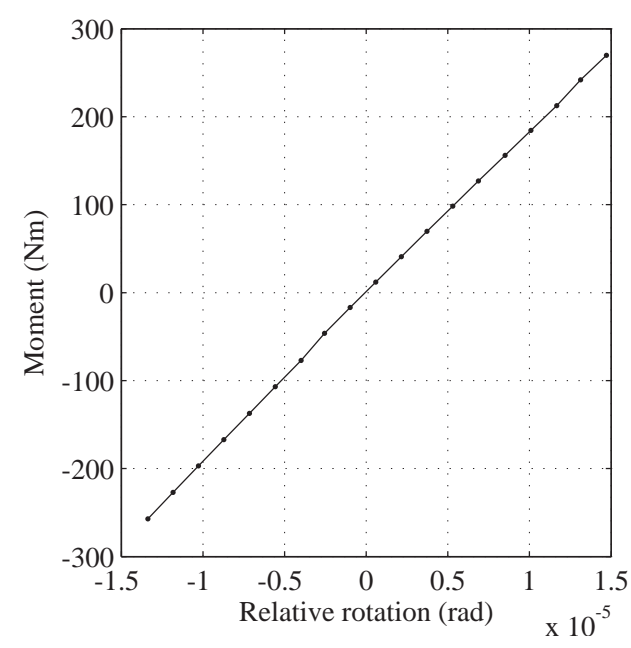

(a)

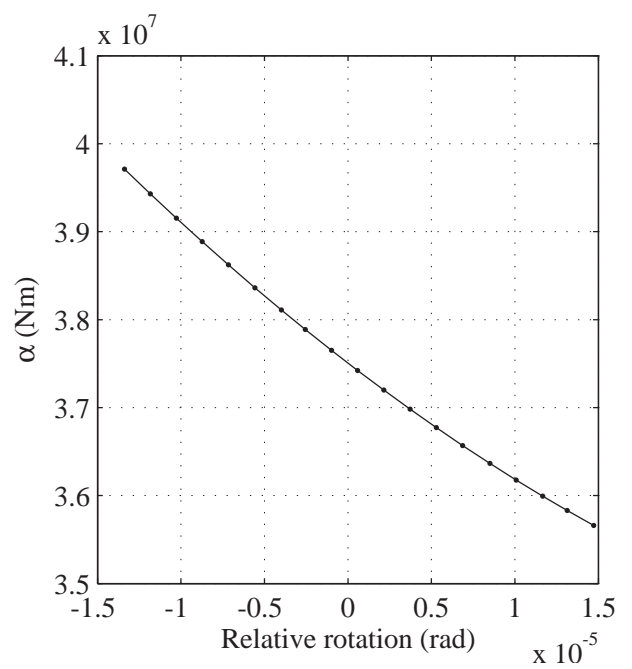

(b)

Figure 20: Typical prediction of the RC beam model for: (a) moment-rotation curve during a vibration cycle (b) $\alpha$-rotation curve during a vibration cycle. 


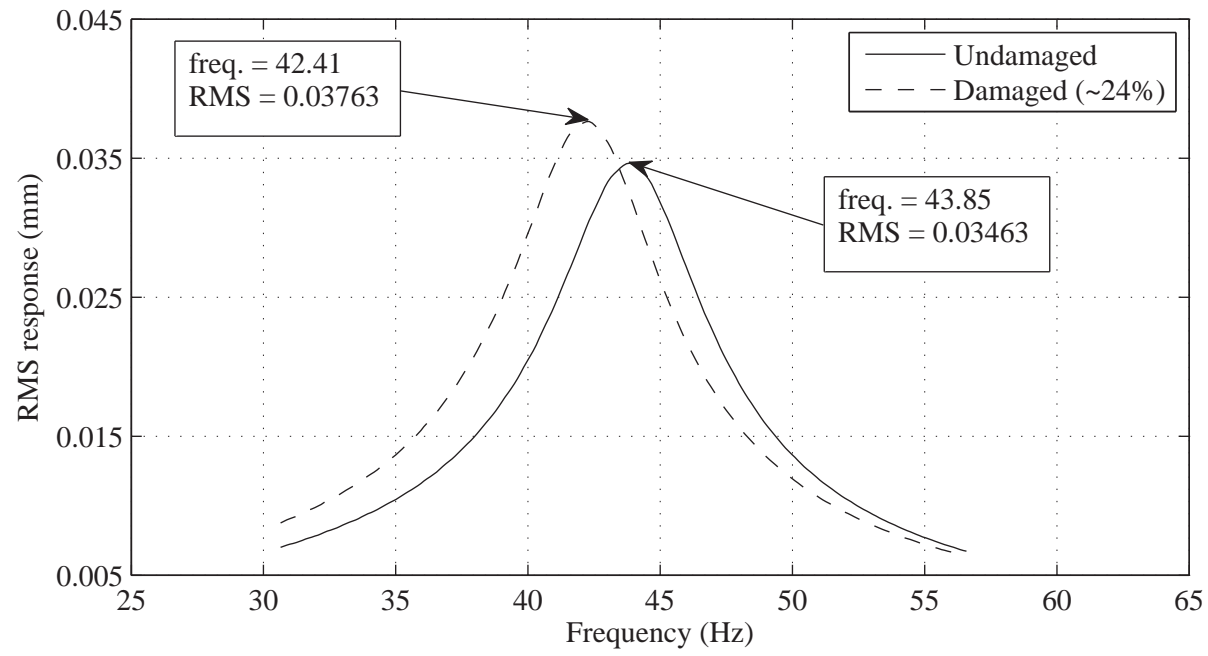

Figure 21: Response of the $\mathrm{RC}$ beam model to a swept sine excitation for an undamaged case and a damaged case. 


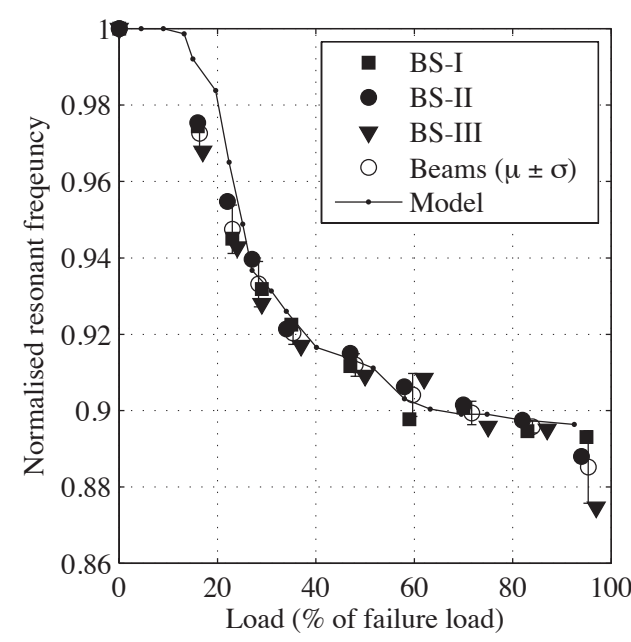

(a)

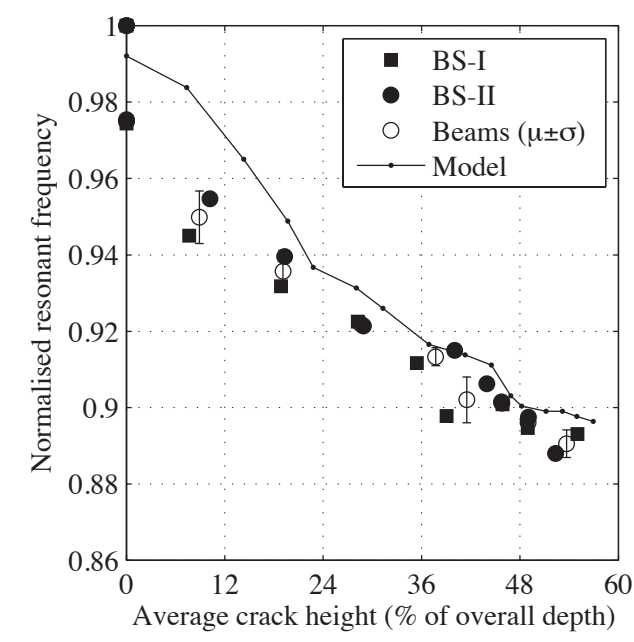

(b)

Figure 22: Comparison of reduction in resonant frequencies between experiments and RC beam model: (a) reduction with damage level (b) reduction with average crack height. 


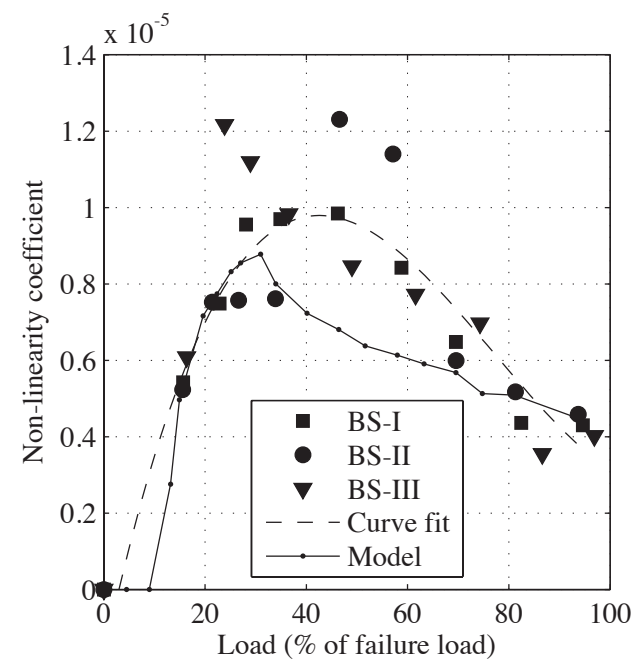

(a)

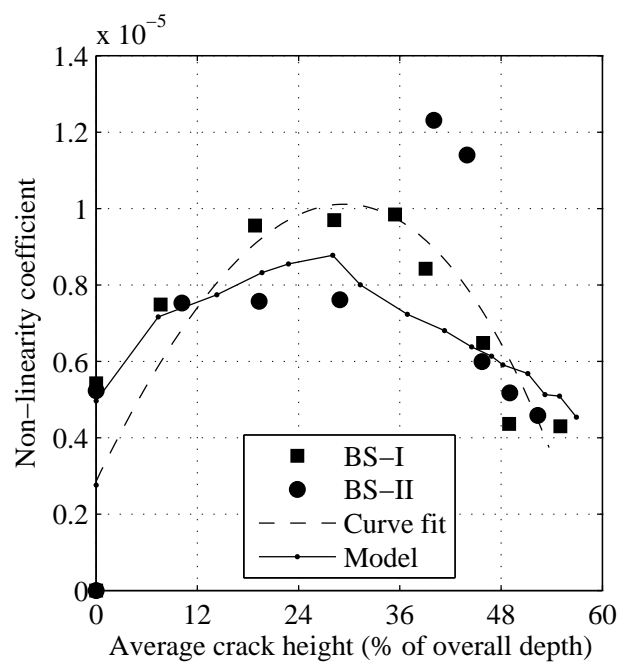

(b)

Figure 23: Comparison of changes in non-linearity between experiments and RC beam model: (a) changes with damage level (b) changes with average crack height. 


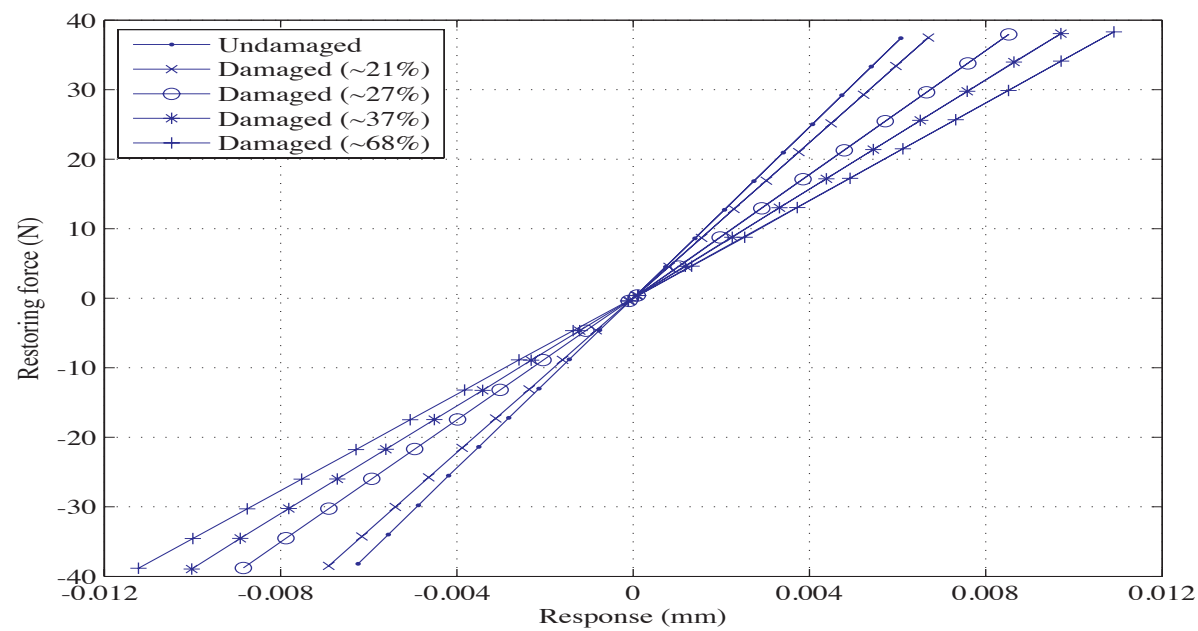

Figure 24: Restoring force-displacement curves for the RC beam model at different damage levels. 


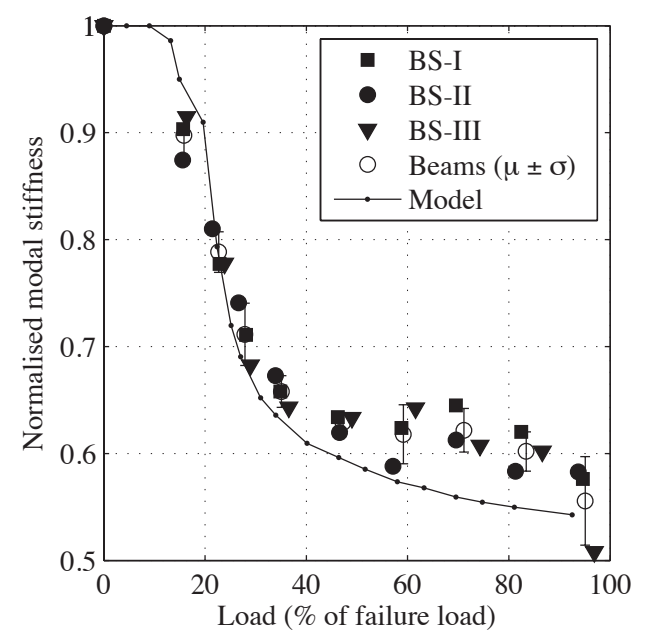

(a)

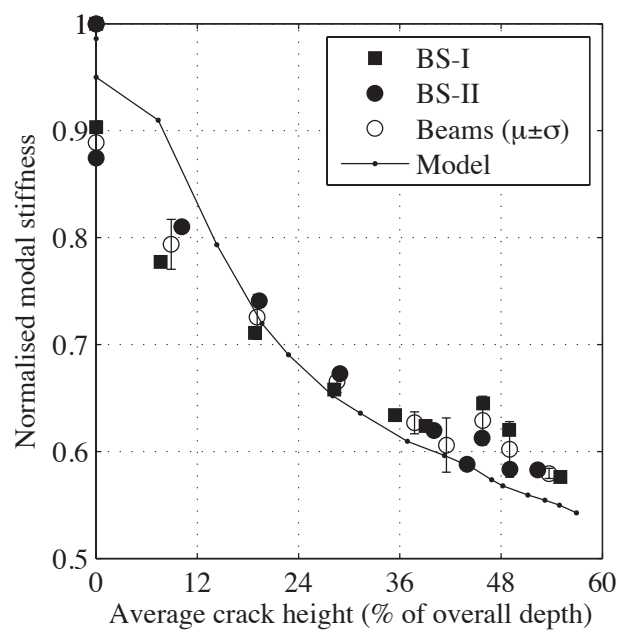

(b)

Figure 25: Comparisons of reduction in modal stiffness between experiments and RC beam model: (a) reduction with damage level (b) reduction with average crack height. 


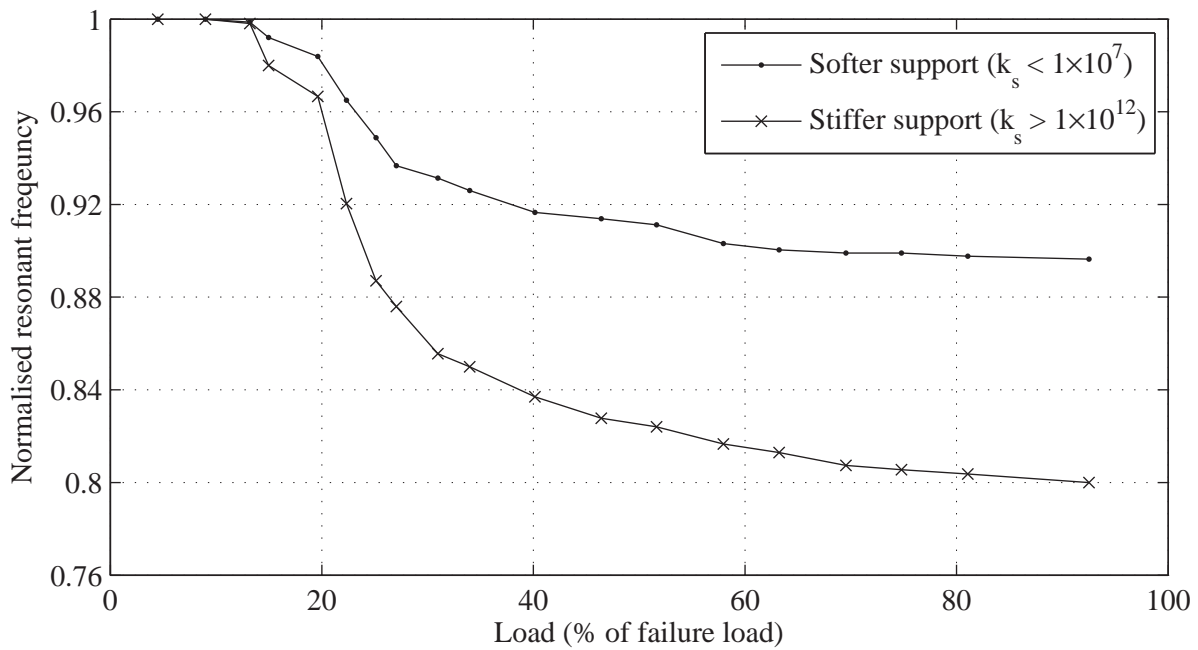

Figure 26: Comparison of reduction in resonant frequency for two types of supports of the RC beam model. 


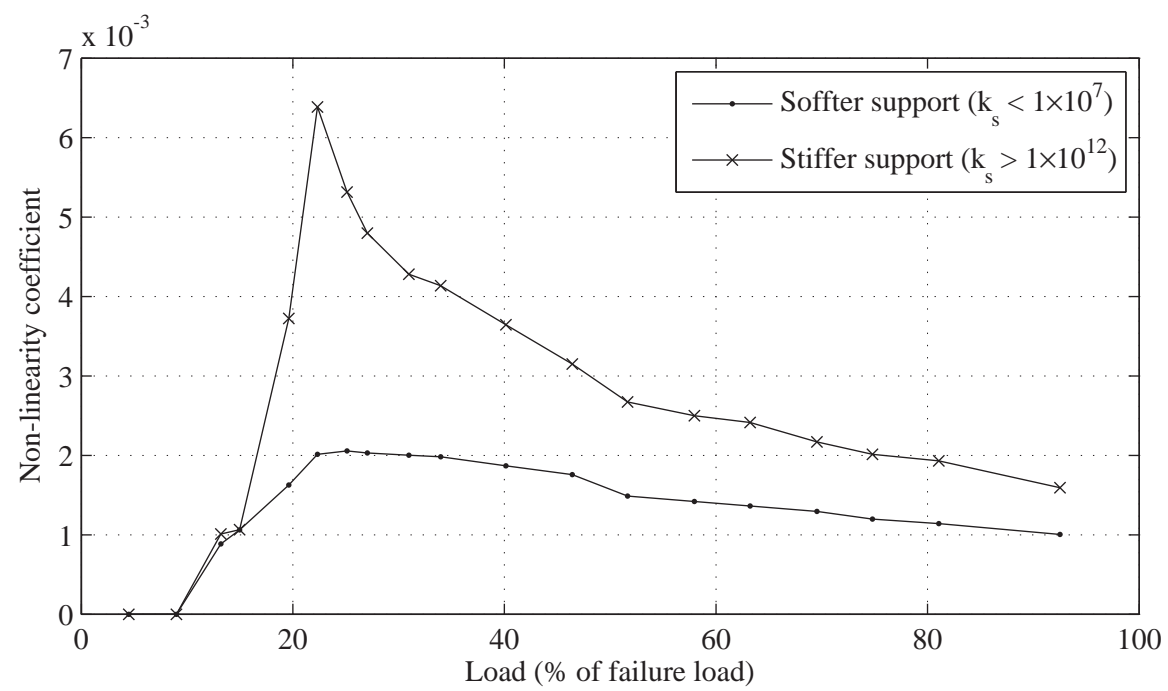

Figure 27: Comparison of changes in non-linearity with damage level for two types of supports of the RC beam model. 


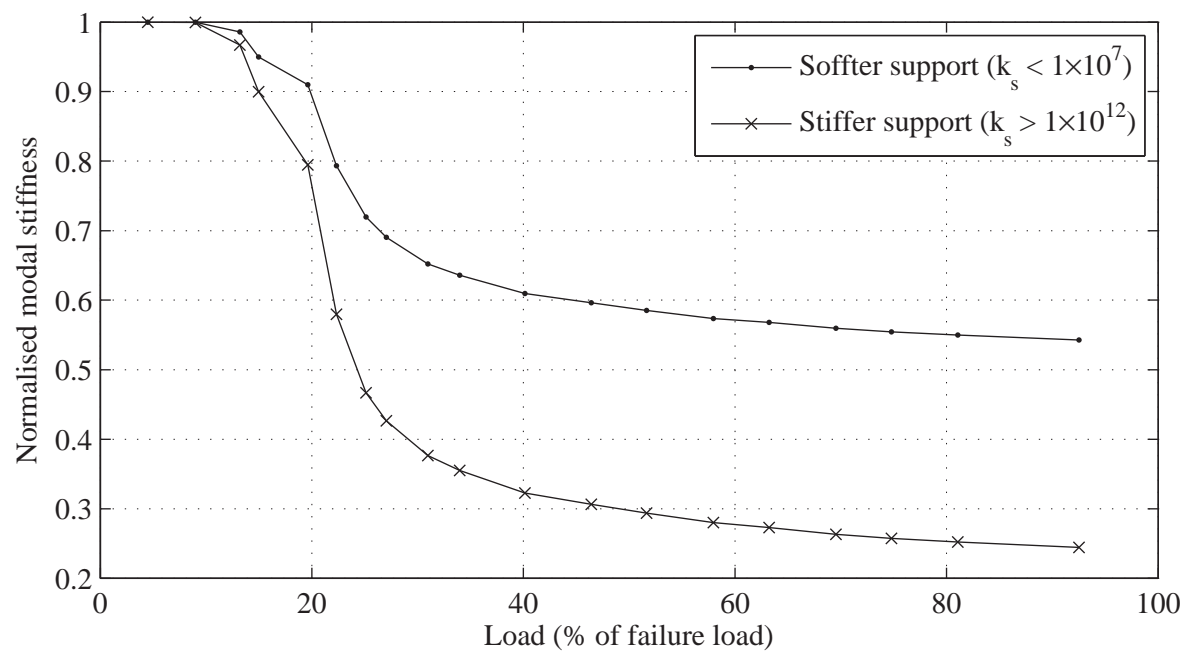

Figure 28: Comparison of reduction in modal stiffness with damage level for two types of supports of the RC beam model. 
(a)
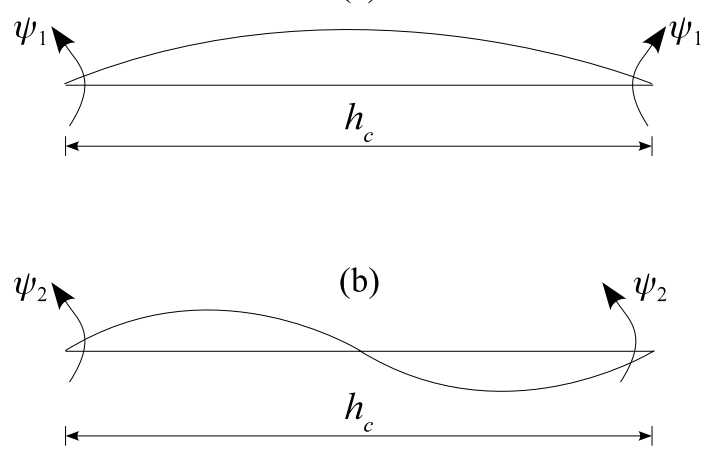

(c)

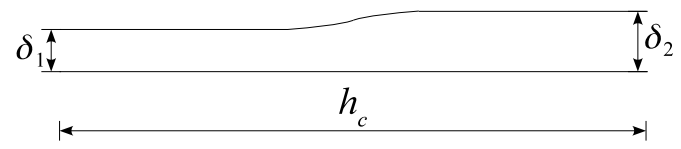

Figure 29: Beam element cases: (a) constant moment (b) end rotations (c) relative displacements. 


\section{List of Tables}

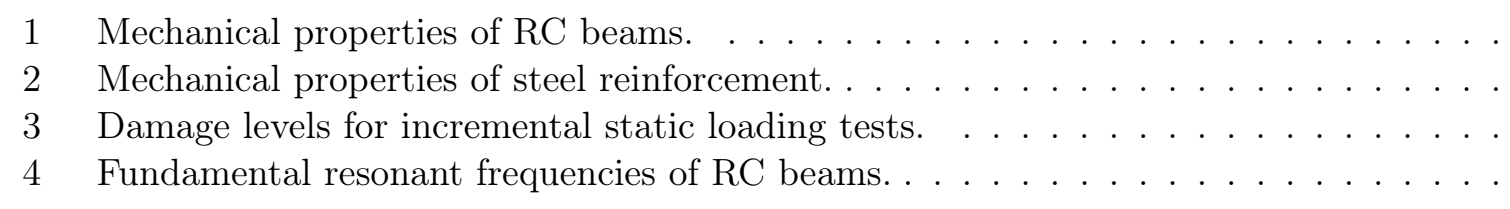


Table 1: Mechanical properties of RC beams.

\begin{tabular}{ccccc}
\hline Beam name $^{a}$ & $\rho\left(\mathrm{kg} / \mathrm{m}^{3}\right)$ & $f_{c u}(\mathrm{MPa})$ & $f_{c t}(\mathrm{MPa})$ & $E_{c}(\mathrm{GPa})$ \\
\hline BS-I & 2360 & 37 & 2.5 & 41.2 \\
BS-II & 2360 & 37.5 & 2.6 & 42.7 \\
BS-III & 2270 & 35 & 2.5 & 37 \\
Mean & 2330 & 36.5 & 2.53 & 40.3 \\
\hline
\end{tabular}

${ }^{a} \mathrm{~B}$ : beam; S: incremental static loading; $\rho$ : density 
Table 2: Mechanical properties of steel reinforcement.

\begin{tabular}{cccc}
\hline Bar type & Diameter $(\mathrm{mm})$ & $f_{y}(\mathrm{MPa})$ & $E_{s}(\mathrm{GPa})$ \\
\hline Plain bar & 6 & 393.6 & 208.4 \\
Type-2 bar & 10 & 540.8 & 199.2 \\
\hline
\end{tabular}


Table 3: Damage levels for incremental static loading tests.

\begin{tabular}{ccccccccccc}
\hline \multirow{2}{*}{ Beam name $(\mathrm{kN})$} & \multicolumn{8}{c}{ Damage level (\% of failure load) } \\
\cline { 2 - 10 } & $1^{\text {st }}$ & $2^{\text {nd }}$ & $3^{\text {rd }}$ & $4^{\text {th }}$ & $5^{\text {th }}$ & $6^{\text {th }}$ & $7^{\text {th }}$ & $8^{\text {th }}$ & $9^{\text {th }}$ & $10^{\text {th }}$ \\
\hline BS-I (41.8) & 0 & 15.7 & 22.9 & 28.1 & 34.9 & 46.2 & 58.8 & 69.5 & 82.4 & 94.6 \\
BS-II (42.6) & 0 & 15.6 & 21.4 & 26.6 & 33.9 & 46.6 & 57.1 & 69.6 & 81.3 & 93.7 \\
BS-III (40.6) & 0 & 16.4 & 23.9 & 28.9 & 36.5 & 49 & 61.6 & 74.3 & 86.6 & 96.9 \\
\hline
\end{tabular}

${ }^{a} \mathrm{~B}$ : beam; S: incremental static loading 
Table 4: Fundamental resonant frequencies of RC beams.

\begin{tabular}{ccccc}
\hline Beam name & $1^{\text {st }}$ mode $[\mathrm{Hz}]$ & $2^{\text {nd }}$ mode $[\mathrm{Hz}]$ & $3^{\text {rd }}$ mode $[\mathrm{Hz}]$ & $4^{\text {th }}$ mode $[\mathrm{Hz}]$ \\
\hline BS-I & 43.03 & 266.10 & 473.10 & 743.10 \\
BS-II & 41.96 & 264.90 & 471.80 & 744.20 \\
BS-III & 42.56 & 264 & 470.60 & 736.30
\end{tabular}

${ }^{a}$ B: beam; S: incremental static loading 